University of Wollongong

Research Online

Faculty of Engineering and Information

Faculty of Engineering and Information

Sciences - Papers: Part A

Sciences

$1-1-2015$

Trace organic contaminants in biosolids: impact of conventional wastewater and sludge processing technologies and emerging alternatives

Galilee U. Semblante

University of Wollongong, gus193@uowmail.edu.au

Faisal I. Hai

University of Wollongong, faisal@uow.edu.au

Xia Huang

Tsinghua University

Andrew S. Ball

RMIT University

William E. Price

University of Wollongong, wprice@uow.edu.au

See next page for additional authors

Follow this and additional works at: https://ro.uow.edu.au/eispapers

Part of the Engineering Commons, and the Science and Technology Studies Commons

Research Online is the open access institutional repository for the University of Wollongong. For further information contact the UOW Library: research-pubs@uow.edu.au 


\title{
Trace organic contaminants in biosolids: impact of conventional wastewater and sludge processing technologies and emerging alternatives
}

\author{
Abstract \\ This paper critically reviews the fate of trace organic contaminants (TrOCs) in biosolids, with emphasis on \\ identifying operation conditions that impact the accumulation of TrOCs in sludge during conventional \\ wastewater and sludge treatment and assessing the technologies available for TrOC removal from \\ biosolids. The fate of TrOCs during sludge thickening, stabilisation (e.g. aerobic digestion, anaerobic \\ digestion, alkaline stabilisation, and composting), conditioning, and dewatering is elucidated. Operation \\ $\mathrm{pH}$, sludge retention time (SRT), and temperature have significant impact on the sorption and \\ biodegradation of TrOCs in activated sludge that ends up in the sludge treatment line. Anaerobic \\ digestion may exacerbate the estrogenicity of sludge due to bioconversion to more potent metabolites. \\ Application of advanced oxidation or thermal pre-treatment may minimise TrOCs in biosolids by \\ increasing the bioavailability of TrOCs, converting TrOCs into more biodegradable products, or inducing \\ complete mineralisation of TrOCs. Treatment of sludge by bioaugmentation using various bacteria, yeast, \\ or fungus has the potential to reduce TrOC levels in biosolids.

\section{Disciplines} \\ Engineering | Science and Technology Studies

\section{Publication Details} \\ Semblante, G. U., Hai, F. I., Huang, X., Ball, A. s., Price, W. E. \& Nghiem, L. D. (2015). Trace organic \\ contaminants in biosolids: impact of conventional wastewater and sludge processing technologies and \\ emerging alternatives. Journal of Hazardous Materials, 300 1-17.

\section{Authors} \\ Galilee U. Semblante, Faisal I. Hai, Xia Huang, Andrew S. Ball, William E. Price, and Long D. Nghiem
}


Trace organic contaminants in biosolids: Impact of conventional wastewater and sludge processing technologies and emerging alternatives

DOI: 10.1016/j.jhazmat.2015.06.037

\author{
Accepted manuscript \\ Journal of Hazardous Materials
}

June 2015

\begin{abstract}
Galilee U. Semblante ${ }^{\mathrm{a}}$, Faisal I. Hai ${ }^{\mathrm{a} *}$, Xia Huang ${ }^{\mathrm{b}}$, Andrew S. Ball ${ }^{\mathrm{c}}$, William E. Price ${ }^{\mathrm{d}}$, and Long D. Nghiem ${ }^{\mathrm{a}}$

${ }^{a}$ Strategic Water Infrastructure Laboratory, School of Civil, Mining and Environmental Engineering, University of Wollongong, Wollongong, NSW 2522, Australia

${ }^{\mathrm{b}}$ State Key Joint Laboratory of Environment Simulation and Pollution Control School of Environment, Tsinghua University, Beijing, 100084, P.R. China ${ }^{\mathrm{c}}$ School of Applied Sciences, RMIT University, Bundoora, 3083, Australia ${ }^{\mathrm{d}}$ Strategic Water Infrastructure Laboratory, School of Chemistry, University of Wollongong, Wollongong, NSW 2522, Australia
\end{abstract}

* Corresponding author:

Email: faisal@uow.edu.au, Ph +61 242213054 


\begin{abstract}
This paper critically reviews the fate of trace organic contaminants (TrOCs) in biosolids, with emphasis on identifying operation conditions that impact the accumulation of TrOCs in sludge during conventional wastewater and sludge treatment and assessing the technologies available for TrOC removal from biosolids. Fate of TrOCs during thickening, stabilisation (e.g. aerobic digestion, anaerobic digestion, alkaline stabilisation, and composting), conditioning, and dewatering is elucidated. Operation $\mathrm{pH}$, sludge retention time (SRT), and temperature have significant impact on the sorption and biodegradation of TrOCs in activated sludge that ends up in the sludge treatment line. Anaerobic digestion may exacerbate the estrogenicity of sludge due to bioconversion to more potent TrOCs and their metabolites. Application of advanced oxidation or thermal pre-treatment may minimise TrOCs in biosolids by increasing the bioavailability of TrOCs, converting TrOCs into more biodegradable products, or inducing complete mineralisation of TrOCs. Treatment of sludge by bioaugmentation using various bacteria, yeast, or fungus has the potential to reduce TrOC levels in biosolids.
\end{abstract}

Keywords: Trace organic contaminants (TrOC); biosolids; sludge digestion; bioaugmentation; advanced oxidation processes

\title{
Table of Contents
}

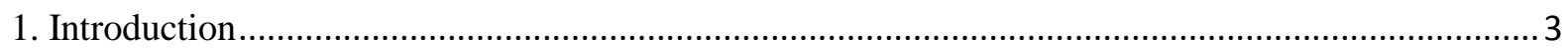

2. Fate of TrOCs in conventional wastewater treatment: mechanisms and relevant factors................... 5

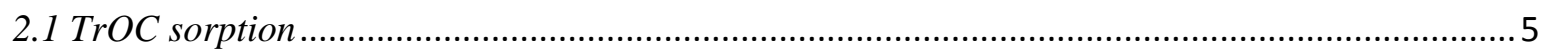

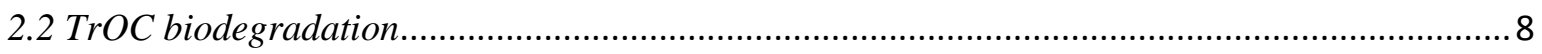

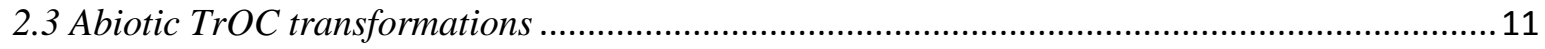

2.4 Operation conditions that impact TrOC accumulation in sludge ............................................ 11

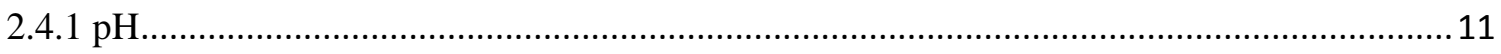

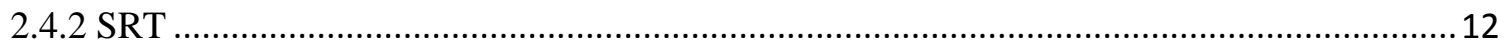

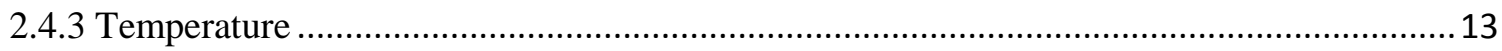

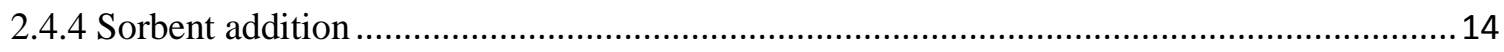

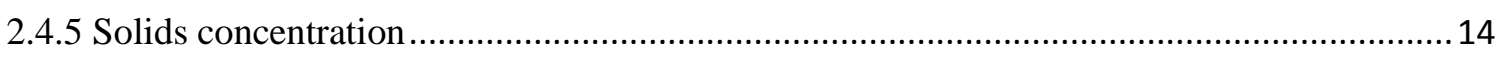

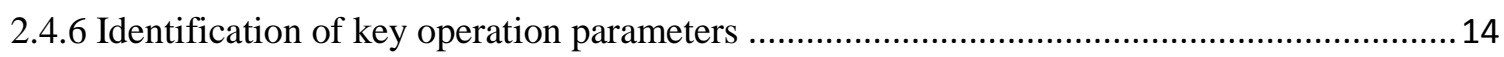


3. Fate of TrOCs during sludge treatment for solids reduction and stabilisation

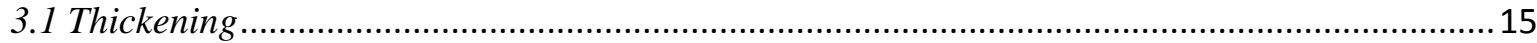

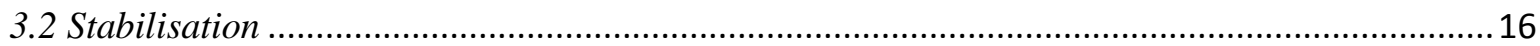

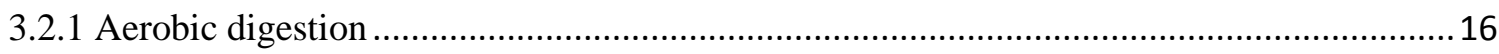

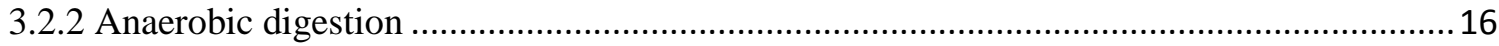

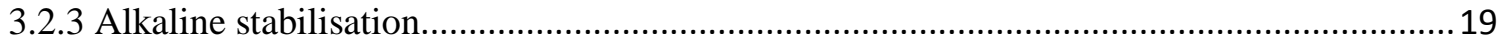

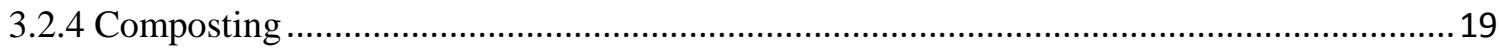

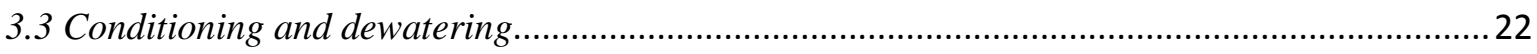

3.2.5 Overall abatement of TrOCs in the sludge treatment line..................................................24

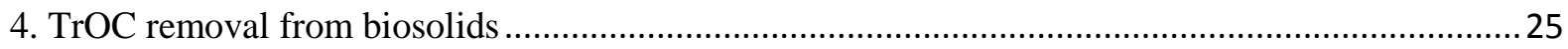

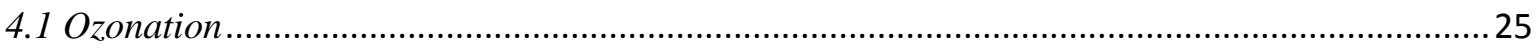

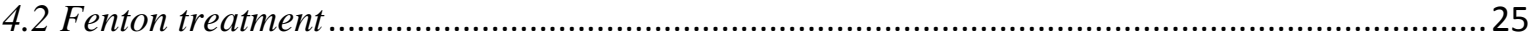

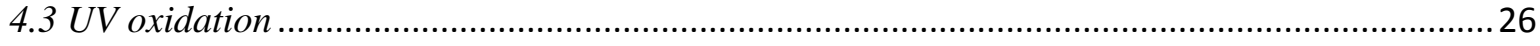

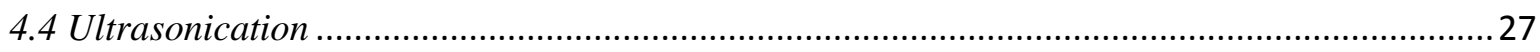

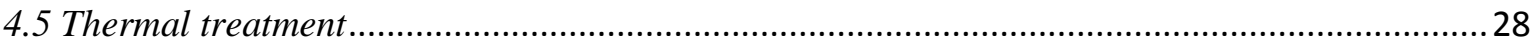

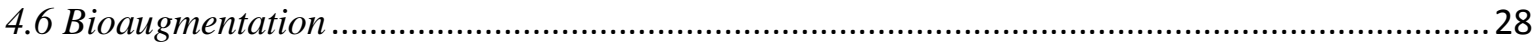

4.7 Future research priorities in TrOC removal from biosolids ..................................................29

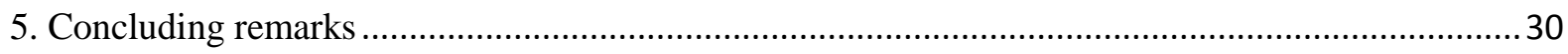

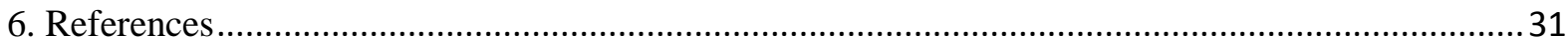

\section{Introduction}

Excess sludge generated by biological wastewater treatment has traditionally been disposed through ocean-dumping, landfilling, or incineration. Due to increasingly stringent environmental regulations, these disposal methods are being phased out and replaced by either aerobic or anaerobic digestion. In these treatment processes, pathogens and volatile solids are removed and sludge is converted to stable "biosolids". Biosolids are rich in organic matter and nutrients, and can be utilised in various land applications (e.g., as fertilizer, soil conditioner and composting material) depending on its quality. Variables such as pathogenicity, vector attraction, odour, and heavy metals content of biosolids are regulated to protect the environment and public safety. The beneficial use of biosolids is a sustainable option because it has minimal impact on the environment (if the final product is devoid of pollutants), enables the recovery of resources, and 
adds economic value to what is conventionally perceived as waste $[1,2]$. Nonetheless, significant concern over the occurrence of trace organic contaminants (TrOCs) in biosolids, which can eventually contaminate soil and water and accumulate in plants and grazing animals, has risen in the recent years [3-5]. These TrOCs include pesticides, industrial chemicals, components of consumer products, pharmaceuticals and personal care products, hormones, and other organic pollutants that are ubiquitous in sewage and other environmental samples. Many of these TrOCs have the potential to cause chronic disorders in animals and humans [3]. TrOCs that are present in biosolids are those which are recalcitrant to wastewater and sludge treatment and have high affinity for sludge flocs. Although a few countries have already imposed controls on certain pollutants, e.g. di(2-ethylhexyl)phthalate (DEHP), linear alkylbenzene sulphonates (LASs), nonylphenol (NP) and nonylphenol ethoxylates (NPEs), polycyclic aromatic hydrocarbons (PAHs), polychlorinated biphenyls (PCBs), polychlorinated dibenzo-p-dioxins and dibenzo-pfurans (PCDD/Fs), a unified directive addressing TrOCs in biosolids is not yet available [6].

The occurrence of TrOCs in biosolids are influenced by wastewater and sludge treatment operation parameters $[4,7]$ and could be minimised by the addition of advanced treatment processes including ozonation [8], ultraviolet (UV) oxidation [9], and bioaugmentation [10] in the sludge treatment line. The fate of TrOCs during wastewater treatment is largely determined by their physicochemical properties (e.g. hydrophobicity, charge, and functional group). Thus, their occurrence in biosolids is inherent and unavoidable. Nonetheless, literature suggests that optimisable operation parameters (e.g. pH, sludge retention time (SRT), and temperature) have some degree of influence on TrOC sorption and biodegradation [7, 11]. Further treatment of biosolids can remove TrOCs with high efficiency, but may require additional equipment and resources that drive up the cost of biosolids management.

The aim of this review is to analyse the occurrence and removal of TrOCs in biosolids. The first part of this review will investigate the underlying mechanisms and factors that affect the fate of TrOCs during wastewater treatment. There is a wealth of research about the fate and removal of TrOCs in the conventional activated sludge (CAS) process [12-18]. A few review articles have summarized the effect of various operation parameters on TrOC removal from the aqueous phase $[7,19,20]$, but none has systematically collated and scrutinised the available data to identify 
operation conditions that are relevant for controlling the occurrence of TrOC in biosolids. The second part will discuss the fate and removal of TrOCs during sludge treatment. Most of the literature available on the fate of TrOCs in the sludge treatment line has focused on conventional aerobic and anaerobic digestion, and much less is known about the behaviour of TrOCs in other sludge treatment processes, e.g. thickening, conditioning and dewatering, and composting. The third part of the review will critically examine the mechanisms and efficiency of the emerging technologies for TrOC removal from biosolids. From these, future research priorities about the management of TrOCs in biosolids will be provided.

\section{Fate of TrOCs in conventional wastewater treatment: mechanisms and relevant factors} Upon entry to WWTPs, TrOC may sorb on sludge flocs, undergo biodegradation or abiotic transformation, or remain intact in wastewater. In general, abiotic loss of TrOCs in primary or secondary wastewater treatment and in sludge treatment is limited (Section 2.3). TrOC sorption on sludge largely depends on their physico-chemical properties, e.g. hydrophobic TrOCs are more likely to partition in the organic portion of sludge (Section 2.1). Although sorption separates TrOCs from wastewater, it does not result to their elimination from the sludge and therefore not a means of "TrOC removal." The sorption of biodegradable compounds on sludge facilitates biodegradation, but sorption of slowly biodegradable compounds lead to contaminant build-up. The liberation of TrOCs from sludge during sludge treatment may increase their bioavailability (i.e., availability for biodegradation). TrOC biodegradation occurs under aerobic, anoxic, and anaerobic conditions (Section 2.2), and may result to complete mineralisation of the compounds. However, formation of metabolites that are potentially more toxic than the parent compounds have been also reported.

\subsection{TrOC sorption}

Activated sludge has a high sorption capacity for TrOCs due to its large specific surface area [4]. Sorption occurs mostly through hydrophobic interactions between TrOCs and the organic fraction of sludge [21, 22]. Li et al. [21] reported a positive correlation between the sorption of antibiotics and the total organic carbon (TOC) of secondary sludges from different WWTPs (e.g. $7-45 \%$ TOC). Similarly, Zhang et al. [22] observed that the sorption of $17 \alpha$-ethinylestradiol 
increased with the TOC of different types of sludge (e.g. 44-47\% TOC). A direct relationship between TrOC sorption and TOC is also observed in other environmental matrices, such as soils (e.g. 5-33\% TOC) and aquatic sediments (e.g. <1-5\% TOC) [23].

Sorption increases with hydrophobicity of TrOCs, which can be quantified using the apparent octanol-water partitioning coefficient $\log D$ :

$$
\log D=\frac{[H X]_{o}}{[H X]_{w}+\left[X^{-}\right]_{w}}
$$

Equation 1

where $[\mathrm{HX}]_{\mathrm{o}}$ is the concentration of the un-ionised form of the compound partitioned in octanol and $[\mathrm{HX}]_{\mathrm{w}}$ and $\left[\mathrm{X}^{-}\right]_{\mathrm{w}}$ are the concentrations of the un-ionised and ionised forms of the compound partitioned in water, respectively, when the octanol-water system is under equilibrium at a given $\mathrm{pH}$ and temperature. According to Hai et al. [24], TrOCs with $\log D>3$ generally have high sorption on sludge. Hydrophobicity depends on the chemical structure of the compound. For example, Niu et al. [25] observed that the sorption of perfluorosulphonate on sludge is significantly higher than that of perfluorocarboxylate because the sulphonate group is more hydrophobic than the carboxylate group. Nonetheless, Taedkaw et al. [26] found that hydrophobic TrOCs that possess electron donating groups (e.g. hydroxyl and amine) do not accumulate in the sludge of an aerobic membrane bioreactor (MBR) due to their high biodegradability.

TrOCs also sorb on sludge by means of electrostatic attraction. The $\mathrm{pH}$ at the isoelectric point (pI) of sludge is 2.9 [27], meaning its surface is negatively-charged under typical biological conditions of $\mathrm{pH}$ 7. Therefore, TrOCs that predominantly exist in their neutral or positivelycharged forms at $\mathrm{pH} 7$ were found to have high sorption in primary and secondary sludge [2830]. On the other hand, TrOCs that are predominantly negatively-charged at $\mathrm{pH} 7$ did not significantly sorb on sludge due to electrostatic repulsion [31]. Favourable electrostatic conditions also facilitate hydrophobic interactions, as noted by Urase and Kikuta [32] when they found that a linear correlation between hydrophobicity and sorption existed only when TrOCs are predominantly in neutral form. However, exceptions have been reported in literature. Calace 
et al. [33] observed that although electrostatic repulsion is expected between negatively-charged chlorophenols and sludge at $\mathrm{pH} 8$, high sorption of the compounds still occurred via hydrophobic binding. Similarly, Stevens-Garmon et al. [28] found that some positively-charged compounds (e.g. trimethoprim and atenolol) that are expected to have high electrostatic attraction with sludge at pH 7 exhibited low sorption due to their hydrophilic nature.

It is also possible that extracellular polymeric products (EPS) can play a significant role in TrOC sorption. EPS are proteins, carbohydrates, humic acids, and other small organic molecules excreted by bacteria that serve as the structural framework of sludge flocs. They are highly hydrophobic, and therefore have greater binding propensity for organic pollutants (e.g. benzene and toluene) than bacterial walls [34]. Thus far, Niu et al. [25] observed a positive correlation between the sorption of perfluoroalkyls and the protein fraction of EPS has been attributed to the linkage of the compounds with the amide group or secondary structure of protein. Likewise, Métivier et al. [35] found that the affinity of erythromycin towards EPS was greater than that of acetaminophen, which may explain why erythromycin has greater sorption on sludge. Khunjar and Love [36] performed TrOC sorption experiments on sludge with and without (i.e., after cation exchange resin extraction) EPS, and observed that $17 \alpha$-ethinylestradiol have greater affinity towards the protein fraction for EPS, whereas trimethoprim sorbed equally on the protein and polysaccharide fractions. Further investigation is required to confirm the relationship of EPS and TrOC sorption, but this is probably challenging because EPS characteristics are sensitive to many factors including wastewater characteristics, bacterial growth phase, and reactor operation conditions [34].

Notably, the irreversible sorption of organic contaminants and their metabolites has been observed in soils [37]. There is limited information on the irreversible sorption of TrOCs on activated sludge, but it is likely to have impact on TrOC bioavailability and treatment. It may also result in non-extractable residues (i.e. compounds that cannot be liberated from the sludge flocs without significantly altering the sludge matrix) and complicate sample extraction and analysis [38, 39]. The eventual liberation of irreversibly bound TrOCs, e.g. when volatile solids are destroyed or sludge is exposed to soil [40,41], is also of environmental concern [39]. The 
release of TrOCs upon destruction of volatile solids has been observed during anaerobic digestion (Section 3.2.1) and advanced oxidation treatment of sludge (Section 4).

\subsection{TrOC biodegradation}

Based on a comprehensive review on TrOC biodegradation, Tran et al. [11] contend that due to their low concentration in wastewater, TrOC biodegradation is most likely to occur via cometabolism. In other words, in many instances, TrOCs do not serve as primary carbon source for microbial growth, and their biodegradation occurs only when other carbon sources are available (e.g. biodegradable COD in wastewater). Co-metabolic pathways may lead to the formation of metabolites that may eventually participate in metabolic reactions resulting in the complete mineralisation of the compounds [11]. Nevertheless, biodegradation of TrOCs by bacterial metabolism, i.e. the utilisation of TrOCs as the primary substrates for bacterial growth, has also been shown in pure bacterial cultures and batch tests using activated sludge [42]. In any case, the biodegradability of TrOCs depends on the chemical structure of the compounds. Those that bear highly branched or short hydrocarbon chains and halogen, sulphonate, methoxy, and nitro moieties are generally recalcitrant $[4,43]$. The sorption potential of TrOCs has a dual effect on biodegradation. The sorption of rapidly biodegradable compounds on bacterial surfaces facilitates their reaction with extracellular enzymes and uptake into cells [4], but the sorption of slowly biodegradable compounds on sludge flocs decreases their bioavailability and exacerbates accumulation in sludge [44, 45]. Barret et al. [44] developed a model for TrOC co-metabolism in anaerobic sludge, and showed that compounds partitioned in the aqueous phase undergo biodegradation. Wijekoon et al. [45] reported that hydrophobic and persistent TrOCs significantly accumulate in the MBR. Treatment at higher SRT can enhance biodegradation by increasing reaction time and enabling growth of slow-growing bacteria [4].

TrOC biodegradation can result in toxic metabolites, which may have a greater impact on the environment and human health than the parent compounds [4, 11]. Some metabolic pathways are well-documented. One of the most notable reactions is the aerobic biodegradation of long chain nonylphenol ethoxylates into short chain nonylphenol ethoxylates followed by the anaerobic degradation of the ethoxylate groups that increases the concentration of nonylphenol in sludge [4, 46]. Metabolites from the biodegradation of pharmaceuticals [42, 47], linear alkyl 
benzene sulfonates [48], and UV filters [49] in sludge were also identified, as well as products from bioconversion among hormones $[50,51]$. However, limited information is available on the biodegradation pathways of TrOCs due to the wide range of compounds in real wastewater, which makes it difficult to relate detected metabolites to the parent compounds [49, 52]. The complexity of the sludge matrix also creates issues in sample extraction and analysis $[49,53]$. Therefore, it is beneficial to observe biodegradation of individual compounds by pure cultures to understand potential reaction pathways in sludge. For instance, some biodegradation products of di(2-ethylhexyl)phthalate and bisphenol A exhibit toxicity and/or estrogenicity [53]. It is also useful to perform toxicity or estrogenic activity assays to evaluate the efficiency of treatment procedures and potential hazards of effluent and sludge to be disposed or re-used [52, 54].

Biodegradation occurs under different redox conditions (aerobic, anoxic, and anaerobic), with each condition offering biodegradation pathways that may not be available in others due to its distinct microbial consortia. Aerobic treatment generally results to high biodegradation of TrOC through the action of heterotrophic bacteria and autotrophic ammonia-oxidizing organisms (AOO) in the form of bacteria and archaea [11]. Using 17 $\alpha$-ethinylestradiol as a model pollutant, several research groups have showed that heterotrophs and AOO utilise the enzymes catechol dioxygenase [55] and ammonia monoxygenase [16] for TrOC degradation, respectively. AOO is necessary for the biodegradation of some pharmaceuticals (e.g. roxithromycin, erythromycin, and iopromide) $[13,17,56]$, although cooperative biodegradation of $17 \alpha$-ethinylestradiol, trimethoprim, and their metabolites by heterotrophs and AOO has been observed [55]. Interestingly, heterotrophic species belonging to the same group have different TrOC biodegradation capacity. Pure cultures of Rhodococcus rhodochrous completely degraded $17 \alpha-$ ethinylestradiol, whereas pure cultures of $R$. equi, $R$. erythropolis, and $R$. zopfii were only able to degrade about $60 \%$ of the same compound [57].

Previous studies generally show that TrOC biodegradation preferentially occurs under aerobic than anoxic conditions [13, 56, 58, 59], The laboratory-scale reactors of Suarez et al. [13] and Dorival-García et al. [56] demonstrated that compounds such as dicloflenac, naproxen and roxithromycin were recalcitrant under anoxic conditions, but had moderate to high removal (e.g. 14.9-60\%) under aerobic conditions. Phan et al. [58] investigated the removal of 30 TrOCs by a 
pilot MBR consisting of an anoxic/anaerobic and an aerobic compartment. They [58] reported that TrOC biodegradation occurred mostly in the aerobic compartment and only a few TrOCs were readily biodegradable under anoxic/anaerobic conditions. Nonetheless, there are also reports of TrOCs having similar or higher biodegradation in anoxic reactors in comparison with aerobic reactors under specific circumstances such as high SRT or low dissolved oxygen (DO) concentration. Suarez et al. [13] noted that synthetic musks (e.g. tonalide and galaxolide) achieved high biodegradation under anoxic conditions with SRT>20 days. Hai et al. [60] and Stadler et al. [59] observed comparable or higher biodegradation of sulfamethaxozale under near-anoxic conditions (e.g. DO concentration $<0.5 \mathrm{mg} / \mathrm{L}$ ), probably because both aerobic and anoxic co-metabolic pathways were available under those conditions. Therefore, a systematic combination of aerobic and anoxic treatment can enhance TrOC removal. Phan et al. [58] showed that anoxic conditions promoted the sorption of hydrophobic TrOCs on sludge, which possibly facilitated their biodegradation during sludge recirculation between aerobic and anoxic conditions. Furthermore, Phan et al. [61] observed that a full-scale MBR with a complex configuration involving multiple aerobic and anoxic zones showed higher and more stable removal of TrOCs than a pilot-scale MBR containing only aerobic and anoxic reactors, emphasizing the role of different DO levels in enhancing the sorption-biodegradation process.

Anaerobic treatment is marked by unique biotransformation pathways, such as reductive dehalogenation of chlorinated compounds, conversion of natural hormones, and enantioselective biodegradation $[4,62,63]$. Reductive dehalogenation of six chlorophenols was observed in upflow anaerobic sludge blanket reactors, and the reaction involved either hydrogenolysis, i.e. the substitution of chlorine atoms with hydrogen, or vicinial reduction, i.e. the removal of two halogens from adjacent carbon atoms resulting to the formation of a double bond [4]. Joss et al. [62] reported that estrone is converted to $17 \beta$-estradiol exclusively under anaerobic conditions. This suggests that although anaerobic treatment can result in moderate to high estrogen removal $[62,64]$, it may have implications on the estrogenicity of sludge. Bioconversion among TrOCs and metabolites was also evident during anaerobic digestion of sludge (Section 3.2.2). Furthermore, the study of Gasser et al. [63] observed that batch anaerobic treatment of the drug $R, S$-venlafaxine and its metabolite $R, S$-O-desmethylvenalfaxine produced degradation products with different enantiomeric distribution than that of aerobic treatment. Wang et al. [65] noted 
high removal (e.g. >93\%) of five polycyclic musks in a laboratory-scale anaerobic MBR through biodegradation, but did not see enantioselectivity in the reactions.

\subsection{Abiotic TrOC transformation}

Abiotic TrOC transformation may occur, but there is a consensus in literature that their impact on TrOC removal from the sludge matrix is limited [53]. A small fraction might be removed via abiotic mechanisms such as volatilisation, hydrolysis, thermal degradation, and photolysis. Volatilisation may occur at ambient temperatures for hydrophilic compounds with relatively low solubility in water and high Henry's law constant $\left(\mathrm{k}_{\mathrm{H}}\right)$ at liquid-gas interfaces, e.g. surface of aeration tanks $[4,66,67]$, or at elevated temperatures, e.g. during composting or thermophilic digestion $[46,68,69]$. Most TrOCs have low $\mathrm{k}_{\mathrm{H}}$ and thus TrOC removal by volatilisation in WWTPs has only been observed for a few compounds (e.g. fragrances and polycyclic hydrocarbons) at minimal quantities $[46,67]$. Hydrolysis has potential to occur in aqueous environments [4], but thus far negligible TrOCs hydrolysis in sludge matrices has been observed $[70,71]$. Thermal degradation of TrOCs has not been substantiated in literature, although the disappearance of pharmaceuticals during sludge drying (e.g. $180^{\circ} \mathrm{C}$ ) has been attributed to this mechanism [40]. Direct or indirect photolysis degrades TrOCs (e.g. pesticides) in aqueous solutions [72], and UV disinfection performed after secondary or tertiary treatment has been observed to remove up to $20 \%$ of pharmaceuticals in the effluent [73]. However, overall photolysis has minimal impact on TrOC removal from sludge matrices $[53,70]$.

\subsection{Operation conditions that impact TrOC accumulation in sludge}

In this section, the operation parameters of secondary and tertiary wastewater treatment that have potential to impact TrOC accumulation in sludge are investigated.

\subsection{1 $\mathrm{pH}$}

The interactions of TrOC and sludge at neutral $\mathrm{pH}$ have been extensively studied [12, 13]. Nonetheless, secondary treatment may occur at higher or lower $\mathrm{pH}$ due to the characteristics of wastewater or addition of chemicals for sludge conditioning [33, 74]. In such cases, the sorption and biodegradation of ionisable compounds is expected to change depending on their $\mathrm{pKa}$ and the surface charge of sludge. Urase and Kikuta [32] found that reducing reactor pH from 7 to 5 increased the sorption of TrOCs containing carboxylic acid groups (e.g. fenoprop) because the un-dissociated and neutral form of the compounds predominated at lower $\mathrm{pH}$. Similarly, Hörsing 
et al. [75] demonstrated that increasing mixed liquor $\mathrm{pH}$ from 6 to 8 caused 10-20\% change (decrease or increase) in the sorption of pharmaceuticals containing nitrogen or amine groups. Clara et al. [74] observed in batch experiments that bisphenol $\mathrm{A}(\mathrm{pKa}=10.2)$ desorbed from sludge when $\mathrm{pH}$ was increased from 7 to 9-12. Notably, $\mathrm{pH}$ is not expected to influence the sorption behaviour of non-ionisable TrOCs. Tadkaew et al. [76] varied the mixed liquor $\mathrm{pH}$ of an MBR from 5-9 and found that the removal of ionisable TrOCs changed with $\mathrm{pH}$, whereas those of non-ionisable TrOCs were independent of $\mathrm{pH}$.

\subsubsection{Sludge retention time}

SRT affects sludge concentration and properties such as EPS composition and hydrophobicity, which may have opposing influence on TrOC sorption [24, 77]. Hence, contradictory results have been reported in literature. For instance, Kim et al. [14] observed that decreasing SRT from 10 to 3 days decreased mixed liquor suspended solids (MLSS) concentration and consequently reduced the sorption of tetracycline by $9 \%$, probably because there were fewer sorption sites at lower sludge concentration. On the other hand, Banihashemi and Droste [78] observed that decreasing SRT from 15 to 5 days increased MLSS concentration due to faster microbial growth rate, and there was no correlation between MLSS concentration and sorption of hormones and pharmaceuticals. These findings imply that MLSS concentration is not the only SRT-dependent factor affecting sludge-TrOC interactions [77]. Lee et al. [79] suggested that increasing SRT may increase EPS concentration, and consequently increase sludge hydrophobicity and affinity towards organic pollutants. The removal efficiencies of TrOC with high sorption (e.g. bisphenol A, estrone, and $17 \beta$-estradiol; $\log \mathrm{D}>3$ at $\mathrm{pH} 8$ ) and moderate sorption (e.g. estriol and bezafibrate; $2<\log \mathrm{D}<3$ at $\mathrm{pH}$ 8) have been found to increase with SRT in different laboratory(SRT $=2$ to 68 days) and full-scale (SRT=0.6 to 550 days) conventional activated sludge (CAS) and MBR plants [12]. Nonetheless, various studies have also identified hydrophobic compounds (e.g. 17 $\beta$-estradiol; $\log \mathrm{D}=4.52$ at $\mathrm{pH} 7$ ) that are unaffected by SRT $[12,15,29]$. Hyland et al. [29] did not see a correlation between SRT and sorption of various ionisable TrOCs. Stasinakis et al. [15] demonstrated that varying SRT (e.g. 3-20 days) had no impact on the sorption of triclosan and bisphenol A, although nonylphenol exhibited high sorption at 3 days. Further investigation must be performed to elucidate the impact of SRT on other sludge properties, such as floc size and density, and their implications on TrOC sorption. 
TrOC biodegradation may increase with SRT due to the (1) increase in sludge biodiversity, and (2) diversification in the metabolic activity of microorganisms due to unavailability of preferred substrate [24]. Clara et al. [12] reported that SRT>10 days is sufficient to degrade most TrOCs and achieve low effluent TrOC concentrations, although recalcitrant compounds such as carbamazepine are unaffected by operation conditions. Tambosi et al. [80] observed that the biodegradation of TrOCs increased when the SRT of an MBR was increased from 20 to 30 days. However, other researchers found that SRT variation at a low (e.g. 3-20 days) [15] and high (e.g. 10-80 days) [62] range did not have any impact on the biodegradation of TrOCs.

\subsubsection{Temperature}

As an enthalpy-driven process, the sorption of TrOCs on sludge due to hydrophobic and electrostatic interactions is temperature-dependent [81]. Temperature also affects biodegradation kinetics and microbial communities [82]. Laboratory-scale studies have demonstrated that temperature variation, which occurs in full-scale plants due to seasonal changes [1], may affect TrOC sorption and biodegradation. For instance, Zeng et al. [83] reported that the sorption of $17 \alpha$-ethinylestradiol on inactivated aerobic and anaerobic sludge was greater at $10{ }^{\circ} \mathrm{C}$ than $30{ }^{\circ} \mathrm{C}$ because Gibbs free energy $\left(\Delta \mathrm{G}^{\circ}\right.$, an indicator of the spontaneity of the process) decreased as temperature decreased. Hai et al. [84] observed that the removal of hydrophobic TrOCs (log D>3) was stable at $10-30{ }^{\circ} \mathrm{C}$, but was unstable and lower at $45^{\circ} \mathrm{C}$. Moreover, the removal of hydrophilic TrOCs $(\log \mathrm{D}<3)$ varied considerably at $10-30{ }^{\circ} \mathrm{C}$ probably because of unstable biodegradation.

Thermophilic secondary treatment of high-strength wastewaters such as those from the pharmaceutical industry may show enhanced organic biodegradation along with low sludge yield [82]. However, it may cause a decline in the removal of hydrophobilic TrOCs as demonstrated by the study of Hai et al. [84]. Wijekoon et al. [85] reported higher TrOC removal in a thermophilic MBR combined with membrane distillation relative to an MBR alone, but the improvement was attributed to TrOC rejection by membrane distillation rather than enhanced organic biodegradation in the MBR under thermophilic conditions. Thus far, the conceptual 
advantage of thermophilic over mesophilic treatment in terms of TrOC removal has not been demonstrated in literature.

\subsubsection{Addition of sorbent materials}

Addition of chemicals such as coagulants and adsorbents is commonly performed to improve sludge properties such as settling [1]. It can also be used to mitigate membrane fouling (in MBRs) and facilitate the removal of TrOCs from the aqueous phase through sorption [86-91]. For instance, activated carbon-amended activated sludge processes rely on enhanced adsorption of TrOCs on sludge followed potentially by their biodegradation. While the sorption of TrOCs on sorbents such as powdered and granular activated carbon (PAC and GAC, respectively) can help improve effluent quality, the conceptual expectation of 'bioregeneration' of the sorbents is often not accomplished [86-89], consequently necessitating periodic withdrawal of the spent adsorbent and its replenishment. The withdrawn sludge contains high concentrations of resistant TrOCs and needs to be properly treated and disposed. Further investigation is required to determine the impact of sorbent addition on TrOC biodegradability and accumulation in biosolids.

\subsubsection{Solids concentration}

TrOC sorption has been found to increase with MLSS concentration [14, 92], probably because higher MLSS affords a greater number of sorption sites for hydrophobic compounds. Li et al. [93] found that $17 \beta$-estradiol biodegradation increased with MLSS concentration ( 0.4 to $1.7 \mathrm{~g} / \mathrm{L})$ in batch experiments, and likewise Shariati et al.[94] noted acetaminophen biodegradation was higher at greater MLSS concentration in an MBR (2-15 g/L) [93, 94]. On the other hand, Li et al. [95] did not observe any impact of MLSS (1-15 g/L) on carbamazepine removal of an MBR. Identifying an optimal MLSS value or range for TrOC biodegradation is difficult since only a few studies have focused on the subject, and they assessed removal of different types of TrOCs.

\subsubsection{Identification of key operation parameters}

Among the operation parameters considered, $\mathrm{pH}, \mathrm{SRT}$, and temperature appear to have the most significant impact on TrOC sorption and biodegradation (Figure 1). Changing the mixed liquor 
$\mathrm{pH}$ for the purpose of sludge conditioning affects TrOC sorption. SRT could be modified to increase the TrOC biodegradation, but further investigation especially on biodegradation of TrOCs at long sludge age is required. Temperature range (e.g. mesophilic or thermophilic) has potential to affect reaction rates and microbial population. The addition of sorbents and solids concentration potentially have impact on TrOC sorption and biodegradation, but due to the lack of literature and/or contradicting reports it is difficult to ascertain their contributions to $\mathrm{TrOC}$ accumulation in sludge.

\section{[Figure 1]}

\section{Fate of TrOCs during sludge treatment for solids reduction and stabilisation}

The objective of sludge treatment is to reduce pathogens [96] and volatile solids [2] in sludge, producing biosolids that can be safely disposed or re-used. TrOCs present in the beginning of the sludge treatment line are those that partitioned in the solid phase of the sludge but were not degraded during secondary or tertiary wastewater treatment. Literature suggests that sludge treatment or handling processes that involve aerobic conditions (e.g. air flotation, aerobic digestion, and composting) favour the biodegradation of TrOCs more than those that involve anaerobic conditions (Section 3.1 and 3.2). Although removal of some TrOCs may occur during physical (e.g. thickening and dewatering) or chemical treatment (e.g. conditioning), significant biodegradation and subsequent removal of TrOCs takes place during sludge stabilisation, particularly under aerobic digestion and composting (Section 3.2).

\subsection{Thickening}

The first step in a typical sludge treatment line is sludge thickening, which is performed to increase the concentration of primary or secondary sludge to $3 \%$ total solids (TS) or more using gravity settling, centrifugation, air flotation, rotary drum filtration, or other procedures [1]. A recent investigation by Marti et al. [97] in full-scale plants revealed that thickening under anaerobic conditions (e.g. gravity settling and centrifugation) had no influence on the fate of estrogens in sludge. The same study showed that that thickening under aerobic conditions (e.g. dissolved air flotation) decreased estrogen concentration in both liquid and solid phases of sludge due to biodegradation [97]. Thickening under aerobic conditions may contribute to TrOC biodegradation in the sludge treatment line, but may require additional energy for aeration and 
water pumping [1]. More systematic study on the impact of thickening on other types of TrOCs is recommended.

\subsection{Stabilisation}

The key process in producing biosolids is sludge stabilisation, which destroys volatile solids to reduce the pathogenicity, vector attraction, and other undesired qualities and prevent spontaneous biodegradation of sludge [1].

\subsubsection{Aerobic digestion}

Aerobic digestion involves the treatment of thickened sludge in a completely mixed aerated reactor that is commonly used by small WWTPs (<22 ML/day) [1] and is notable for greater biodegradation of TrOCs such as nonylphenol/nonylphenol ethoxylates, hormones, and polycyclic hydrocarbons compared to anaerobic digestion [98-101]. Reports to date usually reveal that TrOCs such as nonylphenol have minimal impact on the organic matter and volatile solids removal efficiency of aerobic digestion [100], but the effect of other compounds is yet to be investigated. Studies suggest that TrOC biodegradation in aerobic digestion is strongly dependent on temperature and SRT [97, 101]. Trably and Patureau [101] reported that the biodegradation of polycyclic aromatic hydrocarbons improved from 50 to $80 \%$ when the aerobic digester temperature increased from 35 to $55^{\circ} \mathrm{C}$, but observed abiotic losses at higher temperatures due to volatilisation. They also noted an increase in polycyclic aromatic hydrocarbon biodegradation by the addition of methanol to sludge, which enhanced the dissolution of TrOCs in the liquid phase. Marti and Batista [97] emphasized that there was appreciable removal of estrogens higher aerobic digester SRT (e.g. 40-60 days) due to longer reaction time.

\subsubsection{Anaerobic digestion}

The industrial demand for anaerobic digestion has increased considerably due to its relatively low operation cost and potential to generate energy [102-104]. However, the persistence of TrOCs in sludge may pose problems to this process. First, methanogens are susceptible to organic pollutants such as chlorophenols, halogenated aliphatics, and N-substituted aromatics [105]. Second, full-scale anaerobic digesters generally have negligible or poor biodegradation of 
TrOCs [97, 99, 106-108], and reports of high TrOC removal are limited to laboratory-scale anaerobic digesters [98, 109]. Third, some anaerobic co-metabolic pathways may produce more potent pollutants, such as the formation of nonylphenol from nonylphenol ethoxylates and 17 $\beta$ estradiol from estrone $[46,50,51]$, which have serious implications on the toxicity and/or estrogenicity of biosolids. The formation of estrogenic byproducts is consistently observed even in the anaerobic digestion of other materials than sludge (e.g. animal manure) [110-112].

\section{[Figure 2]}

It was highlighted in Section 2.1 that TrOC removal efficiency of wastewater treatment can be predicted using the hydrophobicity of TrOC as represented by $\log \mathrm{D}$. However, during anaerobic digestion, a relationship between TrOC removal and $\log \mathrm{D}$ could not be derived from available literature $[8,47,51,98,106,109,113-119]$. TrOCs with high $\log \mathrm{D}$ (e.g. $17 \alpha$-ethinylestradiol and triclosan) may exhibit lower removal than TrOCs with lower log D (e.g. ketoprofen and dicloflenac), and vice versa (Figure 2). Narumiya et al. [106] demonstrated that although TrOC sorption on anaerobic digester sludge still depends on its hydrophobicity and/or charge at a given $\mathrm{pH}$, it does not seem to have correlation with biodegradation. Variation in TrOC removal in literature (Figure 2) may be due to varying anaerobic digester conditions and solids destruction efficiency. Studies suggest that TrOC removal in anaerobic digestion could be correlated with solids destruction, which potentially increases the bioavailability of the compounds. For example, Patureau et al. [46] and Trably et al. [120] observed that the removal of nonylphenol ethoxylates and polycyclic aromatic hydrocarbons increased with the TS removal of the anaerobic digester, possibly due to the desorption of the compounds from destroyed flocs and loss of sorption sites. However, Marti and Batista [97] speculated that although estrogen desorbs as sludge flocs are destroyed, it sorbs again on the remaining flocs leading to an increase in estrogen concentration in the solid phase.

\section{[Figure 3]}

The operation conditions of anaerobic digesters (e.g. temperature, type of sludge, SRT) could affect sorption, reaction rates, and microbial community, and thus have potential to impact on the 
fate of TrOC in anaerobic digestion. The effect of temperaturediffers with the type of TrOC (Figure 3) . Studies concur that thermophilic digestion favours the removal of polycyclic aromatic hydrocarbons $[44,120,121]$ especially those with higher molecular weight [120], but different trends are reported for hormones, nonylphenol/nonylphenol ethoxylates, and pharmaceuticals [8, 47, 51, 98, 116, 119]. For instance, Paterakis et al. [119] reported that increasing digester temperature from mesophilic $\left(35 \pm 0.2{ }^{\circ} \mathrm{C}\right)$ to thermophilic $\left(55 \pm 0.2{ }^{\circ} \mathrm{C}\right)$ enhanced the removal of estrone, but increased the bioconversion among hormones leading to a decrease in the removal of estriol and significant formation of 17/-estradiol. The same study also observed that thermophilic conditions enhanced the biodegradation rate of small nonylphenol ethoxylates (e.g. $\mathrm{NP}_{1} \mathrm{E}$ or $\mathrm{NP}_{2} \mathrm{E}$ ) by nearly $100 \%$, but only increased the removal of large nonyl polyethoxylates (e.g. $\mathrm{NP}_{\mathrm{n}} \mathrm{E}$ where $\mathrm{n}=3-12$ ) by $23 \%$. Compared to Paterakis et al. [119], Patureau et al. [46] observed only a $20 \%$ increase in nonylphenol and nonylphenol monoethoxylate removal by increasing digestion temperature from mesophilic to thermophilic, probably because of different experimental conditions (e.g. SRT). Since mesophilic and thermophilic digestion each provides unique biodegradation pathways, a temperature-phased anaerobic digestion configuration has potential to improve overall TrOC removal. Samaras et al. [51] found that twostage thermophilic-mesophilic digestion had higher removal of triclosan, bisphenol A and nonylphenol than either single-stage mesophilic or thermophilic digestion, but did not improve the removal of other compounds such as ibuprofen and naproxen. Notably, Carballa et al. [8] also did not observe changes in the removal of ibuprofen, naproxen, and other pharmaceuticals due to thermophilic digestion, indicating that the biodegradation of such compounds are not dependent on temperature.

Primary and secondary sludge have different composition and floc properties [1]. Paterakis et al. [119] reported that the removal of estrogen and nonylphenol ethoxylates from mixed sludge was $20-80 \%$ higher than that of primary sludge, but a clear explanation for this was not provided. SRT has been found to have significant impact on the sorption and biodegradation of TrOCs during wastewater treatment (Section 2.3.2), but so far only a few studies have investigated the effect of SRT on TrOC removal of anaerobic digestion. Carballa et al. [122] covered a range of SRTs under mesophilic (SRT=10, 20, and 30 days) and thermophilic (SRT=6, 10, and 20 days) conditions, but did not see significant difference in the removal of various hormones and 
pharmaceuticals due to SRT. On the other hand, Hamid and Eskicioglu [123] found that amount of estrone and androstenedione in the supernatant of a thermophilic anaerobic digester increased by 1.2-1.5 and 2-4 times, respectively, when SRT was increased from 5 to 20 days probably due to bioconversion among hormones or other compounds in sludge (e.g. sterols).

\subsubsection{Alkaline stabilisation}

Alkaline treatment is a relatively inexpensive process that involves the addition of materials such as lime, fly ash, or cement kiln dust to raise sludge $\mathrm{pH}$ to 12 for one day or longer. The drastic change in $\mathrm{pH}$ is expected to alter the sorption behaviour of ionisable TrOC. Ivashechkin et al. [124] found that increasing sludge $\mathrm{pH}$ to 12.4 using calcium hydroxide caused desorption of BPA (pKa=10.3) from flocs. Likewise, Kim et al. [125] observed that the concentration of polybrominated diphenyl ethers in sludge decreased after alkaline treatment because of dilution. Conceptually, the partitioning of TrOCs in the aqueous phase may enhance their removal from the sludge matrix after dewatering or increase their bioavailability in further sludge treatment (e.g. digestion). Nonetheless, Kouloumbos et al. [41] reported that the removal of radiolabelled nonylphenol $(\mathrm{pKa}=10.7)$ from the solid phase of sludge was minimal (e.g. 1.3\%) after alkaline stabilisation (e.g. treatment at $\mathrm{pH} 11$ using calcium hydroxide) and centrifugation. The impact of alkaline treatment became apparent when sludge was applied on soil wherein the leaching of nonylphenol increased. Further study is necessary to confirm this trend as the extractability of other non-biodegradable organic components of sludge (e.g. humic acids and lipids) was reported to increase after alkaline stabilisation [126]. Furthermore, Carballa et al. [122] found that alkaline pre-treatment of mixed sludge ( $70: 30$ by volume of primary and secondary sludge) at $\mathrm{pH} 12$ for 24 hours did not enhance the pharmaceutical removal efficiency of a laboratoryscale anaerobic digester. On the other hand, alkaline post-treatment of sludge may enhance the transmission of TrOCs from biosolids to receiving soils and have implications on the TrOC biodegradation pathways in the soil matrix [3].

\subsubsection{Composting}

Composting is an aerobic process that is applied as either a primary or supporting procedure to stabilise dewatered sludge (e.g. TS $>20 \%$ ). In this process, sludge is mixed with one or more types of bulking agents (e.g. wood chips, sawdust, and garden waste) and then incubated in a 
vessel or pile with or without aeration for an extended period (e.g. 21 days or more) [1]. Sanz et al. [133] highlighted that spiking high concentrations (e.g. $230 \mathrm{~g} / \mathrm{kg}$ ) of linear alkyl sulphonate, nonylphenol, and bis(2-ethylhexyl) phthalate to a laboratory-scale in-vessel compost did not have negative impact on composting efficiency and TrOC removal, nonetheless further investigation using other types of TrOCs must be performed. Significant TrOC removal (e.g. $>60 \%$ ) of linear alkyl sulphonate [132, 133], nonylphenol [68, 130-132], polycyclic aromatic hydrocarbons [129], and certain pharmaceuticals (e.g. ciprofloxacin and norfloxacin) [40] have been reported depending on composting conditions (Table 1). However, low removal was observed for TrOCs such as polychlorinated dibenzodioxins [69], hormones [128], and other pharmaceuticals (e.g. sulfamethoxazole and fluoxetine) [40, 127, 128] , and contradicting trends are reported for the removal of di(2-ethylhexyl) phthalate $[68,132]$ and polychlorinated biphenyls $[68,69]$. Notably, there is similarity in the TrOC removal of composts of different materials, e.g. sludge, manure, and municipal solid waste [40,112, 131]. For example, the removal of fluoroquinolones and sulfonamides from sludge (e.g. 46-98\%) was similar to that observed from manure (e.g. 37-100\%) [40, 112]. The study of Moeller and Lee [131] demonstrated that composting sludge (e.g. 50\% moisture) and municipal solid waste (e.g. $60 \%$ moisture) under the same process temperature results to comparable removals of nonylphenol and nonylphenol ethoxylates. Further investigation is necessary to validate these findings, but results thus far show the versatility and robustness of the composting process in terms of TrOC removal.

\section{[Table 1]}

The mechanism of TrOC removal during composting is generally attributed to microbial degradation $[68,69,133,135]$, although volatilisation of compounds with relatively high Henry's constant $\mathrm{k}_{\mathrm{H}}$, (e.g. nonylphenol and polychlorinated biphenyls) has also been observed [68]. Gibson et al. [68] reported that more volatile polychlorinated biphenyls $\left(\mathrm{k}_{\mathrm{H}}=24-40\right.$ $\mathrm{Pa} \cdot \mathrm{m}^{3} / \mathrm{mol}$ ) bearing less chlorine atoms have greater removal during composting than less volatile compounds $\left(\mathrm{k}_{\mathrm{H}}=9-15 \mathrm{~Pa} \cdot \mathrm{m}^{3} / \mathrm{mol}\right)$ bearing more chlorine atoms. Muñoz et al. [69] observed greater polychlorinated biphenyl removal through biodegradation and volatilisation (e.g. 55\%) than that of Gibson et al. [68] (e.g. negligible to 18\%) probably due to dissimilar 
composting environments (Table 1). Compounds with similar structure may undergo different biodegradation pathways. For instance, Muñoz et al. [69], reported that the concentration of polychlorinated biphenyls in the compost decreased by about 55\% after 12 months of incubation probably due to biodegradation, but that of polychlorinated dibenzodioxins (e.g. octachlorodibenzodioxin and 1,2,3,4,6,7,8-heptachlorodibenzo-p-dioxin) doubled probably due to bioconversion from chloropenols.

The fate of TrOCs during composting depends on the type of bulking agent, sludge-to-bulking agent ratio, type of sludge, temperature, and composting time. Bulking agents are carbon-based materials added to the compost to provide structure and regulate odour, but they can adsorb organic compounds and therefore limit the bioavailability of TrOCs. Oleszczuk [129] found that the addition of 20-30\% fly ash to the compost decreased the biodegradation of PAHs from 87.5 to $83 \%$ due to the sorption of polycyclic aromatic hydrocarbons on fly ash. On the other hand, the addition of $30 \%$ sawdust had minimal impact on polycyclic aromatic hydrocarbon biodegradation probably due to its low sorption capacity. Meanwhile, Das and Xia [135] found that decreasing the ratio of sludge and wood chips from 65:35 to 43:57 significantly decreased the half-life of nonylphenol, probably due to the enrichment of nonylphenol-degrading microorganisms at lower carbon to nitrogen ratio in the compost. The importance of the nutritional makeup of the compost to TrOC removal is also apparent in batch cultures of composted sludge by Sanz et al. [133], which exhibited 10-20\% increase in the removal of linear alkylbenzene sulphonates upon supplementation of glucose, tryptone soy broth, yeast extract, or peptone.

Marttinen et al. [134] suggested that the type of sludge may have implications on $\operatorname{di}(2-$ ethylhexyl)phthalate biodegradation during composting. There was greater biodegradation of di(2-ethylhexyl)phthalate from raw sludge (58\%) than anaerobically digested sludge (34\%) after composting, probably because raw sludge had higher moisture content and/or digested sludge already underwent several biological treatment processes and only retained highly persistent fractions. The di(2-ethylhexyl)phthalate removal observed by Gibson et al. (2007) from anaerobically digested sludge was higher than that reported by Marttinen et al. (2004). However, 
it is noteworthy that these studies were conducted at different conditions (e.g., temperature profile, bulking agent, and composting period), and thus, a a direct comparison is not possible.

The effect of temperature on TrOC biodegradation during composting appears to vary according to the type of TrOC. Xia et al. [130] found that increasing the temperature from $24{ }^{\circ} \mathrm{C}$ to $45-65$ ${ }^{\circ} \mathrm{C}$ significantly enhanced the biodegradation rate of nonylphenol. However, Moeller and Lee [131] observed thermophilic composting may facilitate the formation of nonylphenol metabolites that increase the toxicity of sludge. Composting at $65-70{ }^{\circ} \mathrm{C}$ for 34 days resulted to the accumulation of nonylphenol and formation of nonylphenol ethoxylates, whereas composting at $35-55^{\circ} \mathrm{C}$ resulted to the reduction of nonylphenol to below $1 \mathrm{mg} / \mathrm{kg}$. On the other hand, Sanz et al. [133] found that linear alkylbenzene sulphonates were significantly reduced in batch cultures of composted sludge incubated at mesophilic conditions $\left(40-45^{\circ} \mathrm{C}\right)$ but not at thermophilic conditions (e.g. $>47^{\circ} \mathrm{C}$ ), probably because only microorganisms that thrive at lower temperature are capable of attacking linear alkylbenzene sulphonates. The findings of Sanz et al. [133] are supported by those of Patureau et al. [136], which showed that the removal of linear alkylbenzene sulphonates from full-scale composts were higher during the fall season (e.g. 30-45 ${ }^{\circ} \mathrm{C}$ ) than in spring season (e.g. $>45^{\circ} \mathrm{C}$ ). Interestingly, the disappearance of other TrOCs such as nonylphenol ethoxylates, polychlorinated biphenyls, and organohalogens during composting and storage of composted sludge varied according to seasonal changes, indicating that biodegradation of such TrOCs is temperature-dependent [136]. Sadef et al. [137] reported that the removal efficiency of fragrances, antibiotics, and industrial chemicals during composting varied with temperature (e.g. 25 to $70{ }^{\circ} \mathrm{C}$ ), suggesting that each compound was degraded by a specific type of organism. For example, TrOCs that were optimally removed at $50{ }^{\circ} \mathrm{C}$ or more were probably consumed by bacteria, whereas those that were removed at lower temperature were probably consumed by actinomycetes and fungi [137]. An investigation of the microbial diversity during composting is needed to completely elucidate TrOC biodegradation pathways.

\subsection{Conditioning and dewatering}

During dewatering by physical or thermal treatment, moisture is removed from sludge such that a 'cake' with $20 \%$ TS or more is produced to increase the performance of additional sludge stabilisation procedures (e.g. composting) and minimise the cost of final sludge handling and 
transport [1]. However, water molecules are tightly bound in sludge flocs due to their biological gel-like structure. Thus, sludge dewatering is commonly preceded by a chemical or thermal sludge conditioning step. In chemical sludge conditioning, materials such as lime, iron salts, and polymer are added into sludge to coagulate small particles into larger aggregates that have greater capacity to release water. In thermal sludge conditioning, sludge is heated to 230 to $290^{\circ} \mathrm{C}$ to evaporate water that is entrapped in sludge flocs [1].

Thus far, there is inconclusive data on the impact of dewatering on the fate of TrOCs in sludge. Some studies reported that dewatering by centrifugation or filter press increased the concentration of TrOCs in dewatered sludge [97, 116]. Muller et al. [116] suggested that the increase in $17 \beta$-estradiol and $17 \alpha$-ethinylestradiol levels after dewatering might be due to the intense treatment conditions of the filter press $\left(200^{\circ} \mathrm{C}, 2 \mathrm{MPa}\right)$ that enhanced the extractability of compounds. However, in that study, dewatering had no effect on other hormones such as estrone and estriol. Marti et al. [97] reported that dewatering non-digested thickened sludge by centrifugation increased its total hormone concentration by $41 \%$, but dewatering anaerobically digested sludge by the same procedure did not affect hormone concentration. Other studies demonstrated that dewatering by either centrifugation or filter pressing do not affect estrogen concentration of the solid phase of sludge $[54,138]$. The impact of thermal dewatering on other types of TrOC is yet to be investigated in detail, but Lindberg et al. [30] have demonstrated the possibility of thermal degradation of fluoroquinolones when sludge pellets underwent thin layer drying at $180{ }^{\circ} \mathrm{C}$ followed by moving belt drying at $105^{\circ} \mathrm{C}$. One could also speculate that high temperature may cause evaporation of relatively volatile compounds such as nonylphenol and polychlorinated biphenyls

As the final or penultimate step in the sludge treatment line, it is interesting to discover the impact of sludge dewatering and conditioning on the mineralisation, degradation, and mobility of TrOCs in biosolids after application on soil. Kouloumbos et al. [41] monitored the biodegradation products, mineralisation products, and mobility of ${ }^{14} \mathrm{C}$-labelled nonylphenol in soil amended with dewatered and conditioned anaerobically digested biosolids, and found that centrifuged biosolids was less penetrable to $\mathrm{O}_{2}$ and have low bioavailability of nonylphenol to microorganisms in the soil. Meanwhile, sludge conditioned by lime had higher leaching potential of nonylphenol due to desorption at high $\mathrm{pH}$, and sludge conditioned by acrylamide-based 
cationic polymer potentially have greater toxicity due to the formation of nitrophenol from the reaction of nonylphenol with the biodegradation products of the polymer [41].

\subsubsection{Overall abatement of TrOCs in the sludge treatment line}

The abatement of TrOCs in the sludge treatment line heavily relies on the type of stabilisation employed. Of the stabilisation types considered in this review, aerobic processes (e.g. aerobic digestion and composting) demonstrate the greatest potential to remove TrOCs and other estrogenic metabolites. Aerobic digestion of thickened sludge achieves high removal of TrOCs such as nonylphenol ethoxylates, hormones, and polycyclic aromatic hydrocarbons depending on reactor temperature and SRT (Section 3.2.1). Similarly, composting of dewatered sludge results to high removal TrOCs such as of nonylphenol ethoxylates, polycyclic aromatic hydrocarbons, linear alkyl sulphonate, and certain pharmaceuticals depending on composting conditions (Section 3.2.4). Although it is interesting to compare the performance of aerobic digestion and composting in terms of TrOC removal, a systematic study on the subject is not yet available. It can be speculated that different reaction pathways arise since they contend with sludge at different levels of treatment and have distinct microbial consortia. In contrast to aerobic digestion or composting, anaerobic digestion appears to achieve lower TrOC removal, and, according to some reports, may exacerbate the estrogenicity of sludge by producing more estrogenic metabolites. Moreover, literature suggests that the sorption of TrOCs on sludge flocs does not necessarily facilitate anaerobic biodegradation (Section 3.2.2). There are only a few studies on the fate of TrOCs during alkaline stabilisation and therefore trends cannot be established. Nonetheless, it has been shown that treatment at elevated $\mathrm{pH}$ levels impacts the partition of certain TrOCs in sludge (Section 3.2.3).

Other steps in the sludge treatment line, particularly those that involve aerobic (e.g. thickening by air flotation) or extreme reaction conditions (e.g. thermal conditioning at 230 to $290^{\circ} \mathrm{C}$ ) may contribute to TrOC removal, but to a lesser extent. Physical sludge thickening and dewatering appear to have minimal impact. Penultimate sludge dewatering and conditioning (e.g. by lime or polymer addition) have potential to decrease TrOC partition in the solid phase of sludge [41, 97, 116], but more investigation is necessary to fully understand their implications, especially TrOC fate upon application of biosolids in soil. 


\section{TrOC removal from biosolids}

\subsection{Ozonation}

The beneficial effect of ozonation on sludge properties, sludge reduction, and TrOC removal from wastewater has been widely studied [20]. Less information is available on the effect of ozonation of sludge or biosolids on TrOC removal, and so far contradicting trends have been reported (Table 2). Bernal-Martinez et al. [139] observed that ozone pre-treatment of sludge at the dosage of $100 \mathrm{mg} \mathrm{O}_{3} / \mathrm{g}$ TS increased the removal of polycyclic aromatic hydrocarbons in a laboratory-scale mesophilic anaerobic digester. In contrast, Carballa et al. [8] found that ozone pre-treatment of sludge at $20 \mathrm{mg} \mathrm{O}_{3} / \mathrm{g}$ TS had no effect on the capacity of mesophilic and thermophilic anaerobic digesters to remove various TrOCs including musks, antibiotics, and hormones. It can be argued that the ozone dosage utilised by Carballa et al. [8] was too low to impact TrOC removal. In that study, ozone pre-treatment was only beneficial to the removal of carbamazepine because it preferentially partitioned on the aqueous phase of sludge and was amenable to ozone treatment [8]. Qiang et al. [141] observed that ozone treatment of sludge at $0.1 \mathrm{~g} \mathrm{O}_{3} / \mathrm{g}$ TS resulted to the desorption and complete removal of estrone, estriol, and $17 \alpha-$ ethinylestradiol, but only to a moderate removal of bisphenol A and nonylphenol due to their strong binding with sludge. This suggests that it is easier for ozone to attack dissolved TrOCs than sorbed TrOCs. Compared to Qiang et al. [141], Lahnsteiner and Vranitzky [140] observed higher removal of nonylphenol because they utilised sludge containing lower concentrations of nonylphenol and nonylphenol ethoxylates. Their study also demonstrated an 18-60\% increase in the removal of polycyclic aromatic hydrocarbons from sludge when ozone dosage was increased (0.021-0.081 $\left.\mathrm{g} \mathrm{O}_{3} / \mathrm{g} \mathrm{TS}\right)$.

\section{[Table 2]}

\subsection{Fenton treatment}

In the Fenton reaction, $\mathrm{H}_{2} \mathrm{O}_{2}$ is decomposed in the presence of $\mathrm{Fe}^{2+}$ to generate a hydroxyl radical $(\mathrm{OH} \cdot)$ that serves as the primary oxidizing agent of contaminants. The low environmental impact of hydrogen peroxide and wide availability of ferrous ion sources provide Fenton treatment an economic advantage over other oxidation processes (e.g. ozone and photocatalytic treatment) that have high energy consumption and potential environmental risks. Fenton 
treatment has resulted to partial removal of polycyclic aromatic hydrocarbons and hormones from sludge, and demonstrated potential to improve the TrOC removal efficiency of aerobic digestion (Table 2). Flotron et al. [142] reported that only a moderate removal of three polycyclic aromatic hydrocarbons was achieved because natural organic matter in sludge competed with the pollutants for $\mathrm{OH}$. radicals. Zheng et al. [143] found that decreasing the $\mathrm{pH}$ of the Fenton reaction mixture from 2 to 4 increased the removal of 11 polycyclic aromatic hydrocarbons from 20 to $30 \%$ due to higher stability of the reaction components at lower $\mathrm{pH}$. $\mathrm{Li}$ and Zhang [144] observed that Fenton treatment eliminated natural hormones from sludge by 70 $98 \%$, resulting to a decrease in sludge estrogenicity as phenolic compounds were converted to cyclohexenone and quinone-like structures. Furthermore, Pham et al. [145] found that Fenton pre-treatment increased the solubilisation of raw sludge (as measured by the ratio of soluble and total chemical oxygen demand) and the desorption of di(2-ethylhexyl)phthalate, and consequently increased the removal of di(2-ethylhexyl)phthalate by aerobic digestion from 72 to $85 \%$.

\subsection{UV oxidation}

$\mathrm{UV}$ treatment of sludge in various configurations (e.g. $\mathrm{UV}$ only, $\mathrm{UV} / \mathrm{H}_{2} \mathrm{O}_{2}$, and $\mathrm{UV} / \mathrm{TiO}_{2}$ ) can result to the removal of TrOCs through oxidative degradation $[9,150]$, and also through the evaporation of volatile or semi-volatile TrOCs when temperature rises during UV irradiation $[146,150]$. It also has potential to enhance biodegradation by oxidising persistent TrOCs into smaller, more biodegradable products [147]. Varying TrOC removal has been observed depending on UV treatment conditions (Table 2) [9, 146, 147]. Salihoglu et al. [146] found that UV treatment caused only 15-21\% removal of polycyclic aromatic hydrocarbons from sludge through volatilisation. On the other hand, $\mathrm{UV} / \mathrm{TiO}_{2}$ treatment with 0.5 and $20 \%$ by weight $\mathrm{TiO}_{2}$ (Degussa P25) resulted to 77 and 63\% removal of polycyclic aromatic hydrocarbons, respectively. $\mathrm{TiO}_{2}$ particles absorb UV light and produce numerous electron-hole pairs that react with oxygen and water molecules to generate hydroxyl radicals. The addition of $\mathrm{TiO}_{2}$ can enhance TrOC removal, but an excessive addition of the particles causes UV scattering in the suspension and decreases treatment efficiency [146]. $\mathrm{UV} / \mathrm{TiO}_{2}$ has high potential to treat polycyclic aromatic hydrocarbons in particular because it results to minimal evaporation of the compound into air since photodegradation is faster than evaporation [150]. Meanwhile, $\mathrm{UV} / \mathrm{H}_{2} \mathrm{O}_{2}$ 
treatment of sludge achieved high removal of natural hormones and bisphenol A (e.g. 89-97\%) and a moderate removal of nonylphenols (e.g. 67\%) [9]. The observed degradation rate constants of the TrOCs under $\mathrm{UV} / \mathrm{H}_{2} \mathrm{O}_{2}$ treatment were 45-197 and 11-53 times greater than those under UV treatment alone and $\mathrm{H}_{2} \mathrm{O}_{2}$ treatment alone, respectively. Keen et al. [147] found that ${ }^{14} \mathrm{C}$ labelled carbamazepine was photodegraded into smaller products containing hydroxyl and carbonyl moieties through $\mathrm{UV} / \mathrm{H}_{2} \mathrm{O}_{2}$ treatment. Furthermore, UV-treatment of wastewater increased the mineralisation of carbamazepine by $45 \%$ in batch tests, indicating that $\mathrm{UV} / \mathrm{H}_{2} \mathrm{O}_{2}$ is a potential pre-treatment process targeting highly recalcitrant TrOCs.

\subsection{Ultrasonication}

Ultrasonic treatment degrades TrOCs in aqueous media by inducing the implosion of cavitation bubbles that generates hydroxyl radicals capable of oxidizing organic matter. Ultrasonic treatment also promotes the desorption of TrOCs from sludge by destroying sludge flocs [50, 121], which generally enhances TrOC removal from sludge (Table 2). Chawla et al. [50] observed that ultrasonic pre-treatment of sludge at 3,000 kJ/L increased the aqueous concentration of estrone in an anaerobic digester. TrOC desorption may increase their bioavailability during sludge stabilisation [121, 148]. Benabdallah El-Hadj et al. [121] found that the ultrasonic pre-treatment of mixed primary and secondary sludge at $11,000 \mathrm{~kJ} / \mathrm{kg}$ TS increased the naphthalene removal efficiency of a mesophilic digester from 34 to $54 \%$ and that of a thermophilic digester from 50 to $65 \%$ due to the solubilisation of the compound. However, ultrasonication did not improve the removal of pyrene due to its strong binding to organic fractions of sludge. Chang et al. [148] observed that ultrasonic pre-treatment of phthalate esters decreased the half-lives in aerobic sludge by $33-68 \%$. There is also evidence that ultrasonic treatment can stimulate microbial activity and further enhance phthalate ester degradation. The findings of Chang et al. [148] are supported by those of Pham et al. [145], which reported that ultrasonic pre-treatment of raw sludge increased the di(2-ethylhexyl)phthalate removal efficiency of an aerobic digester from 72 to $89 \%$. This enhancement is possibly owed to the solubilisation of sludge, which caused greater mass and oxygen transfer during aerobic degradation. 


\subsection{Thermal treatment}

Exposure of sludge to heat has been reported to induce degradation and evaporation of TrOCs $[30,146]$, but thus far thermal treatment has been found to have varying impact on TrOC removal from sludge (Table 2). Mcnamara [149] reported that thermal hydrolysis of raw sludge at $150^{\circ} \mathrm{C}$ and 5.1 bar for 2 hours deteriorated the biodegradation of nonylphenol ethoxylates in a laboratory-scale mesophilic anaerobic digester, probably due to an increase in volatile fatty acids that inhibited nonylphenol ethoxylate-degrading microorganisms or competed with nonylphenol ethoxylates as substrate [149]. Hamid and Eskicioglu [123] showed that the treatment of dewatered sludge cake in a microwave reactor operating at constant wavelength of $2.45 \mathrm{GHz}$, $1200 \mathrm{~W}$, and 35 bars and varying temperature $\left(80,120\right.$, and $\left.160^{\circ} \mathrm{C}\right)$ decreased the total concentration of 16 hormones by up to $69 \%$ due to auto-oxidation and/or denaturation of the compounds under extreme conditions. Moreover, microwave pre-treatment of sludge at 80, 120 or $160^{\circ} \mathrm{C}$ increased the hormone removal of an aerobic digester by 42,52 , and $78 \%$, respectively. Carballa et al. [122] found that thermal pre-treatment of mixed sludge by autoclaving at $130^{\circ} \mathrm{C}$ for 1 hour had no impact on the removal of various pharmaceuticals, musks, and hormones, but a clear reason was not provided.

\subsection{Bioaugmentation}

Bioaugmentation is a treatment procedure that involves the addition of exogenous microorganisms to enhance the biodegradation of contaminants. So far, only a few studies have investigated TrOC removal from sludge by bioaugmentation with different organisms such as bacteria, yeast, and fungi (Table 3). Larsen et al. [151] augmented digested sludge with Proteiniphilum acetatigenes, a bacteria that degrades polycyclic aromatic hydrocarbons in synthentic media under anaerobic methanogenic conditions, and found improvement in the removal of low and high molecular weight polycyclic aromatic hydrocarbons. Boon et al. [152] inoculated the bacteria Comamonas testosteroni to activated sludge and observed a 50\% removal of 3-chloroanline from the aqueous phase. Hesham et al. [153] observed that the augmentation of a mixture of five strains of yeast (Pichia anomala, Sporidiobolus salmonicolor, Pichia guilliermondii, Rhodotorula dairenensis, and a Candida maltosa-like strain) to an aerated bioreactor increased the removal of chrysene and benzo(a)pyrene from zero to $90.7 \%$ and $80.7 \%$, 
respectively. An enrichment of the yeast strains in activated sludge was observed, as well as an abundance of catechol 2,3-dioxygenase that is responsible for benzene ring cleavage.

\section{[Table 3]}

White-rot fungi (WRF) are well-known for their ability to co-metabolically degrade a wide range of TrOCs from wastewater and soils through enzymatic action [158]. Mixed cultures of bacteria and WRF have been found to remove TrOCs from wastewater via biodegradation and biosorption [158, 159]. There is also evidence that WRF can eliminate TrOCs from biosolids. The research group of Rodriguez-Rodriguez found that the augmentation of Trametes versicolor to sterilised dewatered sludge caused $40 \%$ to complete removal of a wide spectrum of TrOCs and significant reduction in sludge toxicity [10, 154-157]. However, treatment of non-sterilised sludge resulted in less efficient TrOC removal (e.g. fewer TrOCs underwent biodegradation) and decline of fungal activity after 21 days [155]. In this context, it is interesting to note the population of the exogenous organism tends to eventually decline due to microbial competition, and therefore a continuous re-inoculation is necessary to maintain appreciable TrOC treatment efficiency. Larsen et al. [151] observed that the re-inoculation of $P$. acetatigenes to digested sludge every two days enabled the reduction of both low and high molecular weight polycyclic aromatic hydrocarbons, whereas single inoculation of the bacteria during start-up only led to the removal of low molecular weight polycyclic aromatic hydrocarbons. Rodríguez-Rodríguez et al. [157] reported that the re-inoculation of T. versicolor to dewatered sludge in the middle of 42 days of treatment caused $80-86 \%$ removal of TrOCs, whereas only $22-69 \%$ removal can be achieved without the re-inoculation step. On the other hand, Hesham et al. [153] was able to maintain stable TrOC removal from an aerated bioreactor co-habited by activated sludge and yeast for 56 days, with yeast being the dominant species in the system.

\subsection{Future research priorities in TrOC removal from biosolids}

The use of advanced oxidation processes has high potential to eliminate TrOCs from biosolids. Among the advanced oxidation processes discussed, ozonation and ultrasonication appear to demonstrate the greatest potential. Literature suggests that ozonation at $0.1 \mathrm{~g} \mathrm{O}_{3} / \mathrm{g} \mathrm{TS}$ or more could result to more than $60 \%$ removal of TrOCs [139-141], and has the potential to provide an 
additional 30-60\% removal of TrOCs in the sludge treatment line if used as pre-treatment for anaerobic digestion [110]. Ultrasonication can increase the biovailability of TrOCs by liberating them from sludge flocs $[50,145]$. Thus far, ultrasonication has been demonstrated to provide an additional 13\% removal of di(2-ethylhexyl)phthalate in anaerobic digestion [115]. Therefore, future research could focus on optimising treatment conditions (e.g. ozonation time and ultrasonic frequency) for TrOC removal and determining by-product formation. Notably, advanced oxidation processes generally achieve high treatment efficiency but have high maintenance cost and energy consumption, and their practical implementation will depend on the cost-effectiveness of the formats introduced to the market. Bioaugmentation using exogenous organisms, being a biological process, is potentially more environmentally friendly and cost effective than advanced oxidation processes [10]. Among the organisms that have been studied (e.g. bacteria, yeasts, and fungi), WRF emerges as a promising option because it removes a wide range of TrOCs that bacteria are typically unable to degrade $[157,160]$. Indeed small-scale studies demonstrate that WRF can significantly remove TrOCs from digested or dewatered sludge $[10,56,154,155,157]$. However, a major limitation impeding its application is that WRF enzymatic activity is prone to disruption due to bacterial contamination [157]. Future research should focus in using WRF as pre-treatment to sludge stabilisation and implementing WRF treatment of biosolids in pilot-scale.

\section{Concluding remarks}

Implementing significant changes to conventional wastewater treatment to minimise the occurrence of TrOCs in sludge is impractical. In particular, it is difficult to pinpoint specific conditions that will mitigate the TrOC accumulation in sludge due to the wide range of TrOC characteristics. However, literature generally shows that aerobic condition results to higher TrOC biodegradation compared to either anoxic or anaerobic conditions, and anoxic condition may promote the sorption of TrOC on sludge. A combination of different redox conditions and careful control of DO levels has potential to facilitate the TrOC sorption-biodegradation process. Operation at SRT of more than 10 days could facilitate the biodegradation of hydrophic and persistent TrOCs. The impact of the use of adsorbents on TrOC accumulation in sludge should be examined in more detail, as it may have ramifications on the treatability of TrOCs during sludge stabilisation. 
Sludge thickening and dewatering by physical methods (e.g. centrifugation) do not affect the sorption of TrOCs in sludge. However, the introduction of air or heat during these steps could facilitate the removal of TrOCs from sludge via biodegradation, thermal degradation, volatilisation, or evaporation. Significant biodegradation of sorbed and dissolved TrOCs occur during sludge stabilisation by aerobic digestion and composting. Anaerobic digestion can also remove TrOCs, but has poor removal of metabolites that may increase the toxicity and estrogenicity of biosolids irrespective of operation conditions (e.g. temperature and SRT). To further improve TrOC removal, pre- or post-treatment of sludge by advanced oxidation or bioaugmentation of sludge using exogenous organisms could be considered. These technologies increase the removal of TrOCs from biosolids by increasing the bioavailability of the compounds and/or converting the compounds into inert or more biodegradable products.

\section{References}

[1] G. Tchobanoglus, F. Burton, H. Stensel, Wastewater engineering: Treatment and reuse, American Water Works Association, New York, 2003.

[2] G.U. Semblante, F.I. Hai, H.H. Ngo, W. Guo, S.-J. You, W.E. Price, L.D. Nghiem, Sludge cycling between aerobic, anoxic and anaerobic regimes to reduce sludge production during wastewater treatment: Performance, mechanisms, and implications, Bioresource Technology, 155 (2014) 395-409. [3] J.A. Citulski, K. Farahbakhsh, Fate of Endocrine-Active Compounds during Municipal Biosolids Treatment: A Review, Environmental Science \& Technology, 44 (2010) 8367-8376.

[4] J. Birkett, J. Lester, Endocrine disrupters in wastewater and sludge treatment processes, IWA publishing, London, 2003.

[5] B.O. Clarke, S.R. Smith, Review of 'emerging' organic contaminants in biosolids and assessment of international research priorities for the agricultural use of biosolids, Environment International, 37 (2011) 226-247.

[6] S.R. Smith, Organic contaminants in sewage sludge (biosolids) and their significance for agricultural recycling, Phil. Trans. R. Soc. A 367 (2009) 4005-4041.

[7] Z.-h. Liu, Y. Kanjo, S. Mizutani, Removal mechanisms for endocrine disrupting compounds (EDCs) in wastewater treatment - physical means, biodegradation, and chemical advanced oxidation: A review, Science of The Total Environment, 407 (2009) 731-748.

[8] M. Carballa, G. Manterola, L. Larrea, T. Ternes, F. Omil, J.M. Lema, Influence of ozone pre-treatment on sludge anaerobic digestion: Removal of pharmaceutical and personal care products, Chemosphere, 67 (2007) 1444-1452.

[9] A. Zhang, Y. Li, Removal of phenolic endocrine disrupting compounds from waste activated sludge using UV, $\mathrm{H}_{2} \mathrm{O}_{2}$, and $\mathrm{UV} / \mathrm{H}_{2} \mathrm{O}_{2}$ oxidation processes: Effects of reaction conditions and sludge matrix, Science of The Total Environment, 493 (2014) 307-323.

[10] C.E. Rodríguez-Rodríguez, A. Jelić, M. Llorca, M. Farré, G. Caminal, M. Petrović, D. Barceló, T. Vicent, Solid-phase treatment with the fungus Trametes versicolor substantially reduces pharmaceutical concentrations and toxicity from sewage sludge, Bioresource Technology, 102 (2011) 5602-5608. 
[11] N.H. Tran, T. Urase, H.H. Ngo, J. Hu, S.L. Ong, Insight into metabolic and cometabolic activities of autotrophic and heterotrophic microorganisms in the biodegradation of emerging trace organic contaminants, Bioresource Technology, 146 (2013) 721-731.

[12] M. Clara, N. Kreuzinger, B. Strenn, O. Gans, H. Kroiss, The solids retention time-a suitable design parameter to evaluate the capacity of wastewater treatment plants to remove micropollutants, Water Research, 39 (2005) 97-106.

[13] S. Suarez, J.M. Lema, F. Omil, Removal of Pharmaceutical and Personal Care Products (PPCPs) under nitrifying and denitrifying conditions, Water Research, 44 (2010) 3214-3224.

[14] S. Kim, P. Eichhorn, J.N. Jensen, A.S. Weber, D.S. Aga, Removal of Antibiotics in Wastewater: Effect of Hydraulic and Solid Retention Times on the Fate of Tetracycline in the Activated Sludge Process, Environmental Science \& Technology, 39 (2005) 5816-5823.

[15] A.S. Stasinakis, C.I. Kordoutis, V.C. Tsiouma, G. Gatidou, N.S. Thomaidis, Removal of selected endocrine disrupters in activated sludge systems: Effect of sludge retention time on their sorption and biodegradation, Bioresource Technology, 101 (2010) 2090-2095.

[16] T. Yi, W.F. Harper Jr, R.D. Holbrook, N.G. Love, Role of particle size and ammonium oxidation in removal of $17 \alpha$ ethinyl estradiol in bioreactors, Journal of Environmental Engineering, 132 (2006) 15271529.

[17] A.L. Batt, S. Kim, D.S. Aga, Enhanced Biodegradation of lopromide and Trimethoprim in Nitrifying Activated Sludge, Environmental Science \& Technology, 40 (2006) 7367-7373.

[18] R.L. Droste, K.J. Kennedy, J. Lu, M. Lentz, Removal of chlorinated phenols in upflow anaerobic sludge blanket reactors, Water Science and Technology, 38 (1998) 359-367.

[19] N. Vieno, M. Sillanpää, Fate of diclofenac in municipal wastewater treatment plant - A review, Environment International, 69 (2014) 28-39.

[20] Y. Luo, W. Guo, H.H. Ngo, L.D. Nghiem, F.I. Hai, J. Zhang, S. Liang, X.C. Wang, A review on the occurrence of micropollutants in the aquatic environment and their fate and removal during wastewater treatment, Science of The Total Environment, 473-474 (2014) 619-641.

[21] W. Li, Y. Shi, L. Gao, J. Liu, Y. Cai, Occurrence, distribution and potential affecting factors of antibiotics in sewage sludge of wastewater treatment plants in China, Science of The Total Environment, 445-446 (2013) 306-313.

[22] Z.H. Zhang, Y.J. Feng, P. Gao, J.F. Liu, N.Q. Ren, Comparing the adsorption and desorption characteristics of $17 \alpha$-ethinylestradiol on sludge derived from different treatment units, Int. J. Environ. Sci. Technol., 9 (2012) 247-256.

[23] L.-J. Zhou, G.-G. Ying, J.-L. Zhao, J.-F. Yang, L. Wang, B. Yang, S. Liu, Trends in the occurrence of human and veterinary antibiotics in the sediments of the Yellow River, Hai River and Liao River in northern China, Environmental Pollution, 159 (2011) 1877-1885.

[24] F.I. Hai, L.D. Nghiem, S.J. Khan, W.E. Price, K. Yamamoto, Wastewater reuse: Removal of Emerging Trace Organic Contaminants by Membrane Bioreactors, in: F.I. Hai, K. Yamamoto, C.H. Lee (Eds.) Membrane biological reactors, IWA publishing, UK, 2014, pp. 165-205.

[25] M. Niu, W. Zhang, D. Wang, Y. Chen, R. Chen, Correlation of physicochemical properties and sludge dewaterability under chemical conditioning using inorganic coagulants, Bioresource Technology, 144 (2013) 337-343.

[26] N. Tadkaew, F.I. Hai, J.A. McDonald, S.J. Khan, L.D. Nghiem, Removal of trace organics by MBR treatment: The role of molecular properties, Water Research, 45 (2011) 2439-2451.

[27] J. Wang, C.P. Huang, H.E. Allen, Surface Physical-Chemical Characteristics of Sludge Particulates, Water Environment Research, 72 (2000) 545-553.

[28] J. Stevens-Garmon, J.E. Drewes, S.J. Khan, J.A. McDonald, E.R.V. Dickenson, Sorption of emerging trace organic compounds onto wastewater sludge solids, Water Research, 45 (2011) 3417-3426. 
[29] K.C. Hyland, E.R.V. Dickenson, J.E. Drewes, C.P. Higgins, Sorption of ionized and neutral emerging trace organic compounds onto activated sludge from different wastewater treatment configurations, Water Research, 46 (2012) 1958-1968.

[30] R.H. Lindberg, U. Olofsson, P. Rendahl, M.I. Johansson, M. Tysklind, B.A.V. Andersson, Behavior of Fluoroquinolones and Trimethoprim during Mechanical, Chemical, and Active Sludge Treatment of Sewage Water and Digestion of Sludge, Environmental Science \& Technology, 40 (2005) 1042-1048. [31] P. Gao, Y. Ding, H. Li, I. Xagoraraki, Occurrence of pharmaceuticals in a municipal wastewater treatment plant: Mass balance and removal processes, Chemosphere, 88 (2012) 17-24.

[32] T. Urase, T. Kikuta, Separate estimation of adsorption and degradation of pharmaceutical substances and estrogens in the activated sludge process, Water Research, 39 (2005) 1289-1300.

[33] N. Calace, E. Nardi, B.M. Petronio, M. Pietroletti, Adsorption of phenols by papermill sludges, Environmental Pollution, 118 (2002) 315-319.

[34] G.-P. Sheng, H.-Q. Yu, X.-Y. Li, Extracellular polymeric substances (EPS) of microbial aggregates in biological wastewater treatment systems: A review, Biotechnology Advances, 28 (2010) 882-894.

[35] R. Métivier, I. Bourven, J. Labanowski, G. Guibaud, Interaction of erythromycin ethylsuccinate and acetaminophen with protein fraction of extracellular polymeric substances (EPS) from various bacterial aggregates, Environ Sci Pollut Res, 20 (2013) 7275-7285.

[36] W.O. Khunjar, N.G. Love, Sorption of carbamazepine, 17 $\alpha$-ethinylestradiol, iopromide and trimethoprim to biomass involves interactions with exocellular polymeric substances, Chemosphere, 82 (2011) 917-922.

[37] B. Gevao, K.T. Semple, K.C. Jones, Bound pesticide residues in soils: A review, Environmental Pollution, 108 (2000) 3-14.

[38] B.W. Brooks, D.B. Huggett, A.B.A. Boxall, Pharmaceuticals and personal care products: Research needs for the next decade, Environmental Toxicology and Chemistry, 28 (2009) 2469-2472.

[39] A.B.A. Boxall, M.A. Rudd, B.W. Brooks, D.J. Caldwell, K. Choi, S. Hickmann, E. Innes, K. Ostapyk, J.P. Staveley, T. Verslycke, G.T. Ankley, K.F. Beazley, S.E. Belanger, J.P. Berninger, P. Carriquiriborde, A. Coors, P.C. DeLeo, S.D. Dyer, J.F. Ericson, F. Gagné, J.P. Giesy, T. Gouin, L. Hallstrom, M.V. Karlsson, D.G.J. Larsson, J.M. Lazorchak, F. Mastrocco, A. McLaughlin, M.E. McMaster, R.D. Meyerhoff, R. Moore, J.L. Parrott, J.R. Snape, R. Murray-Smith, M.R. Servos, P.K. Sibley, J.O. Straub, N.D. Szabo, E. Topp, G.R. Tetreault, V.L. Trudeau, G. Van Der Kraak, Pharmaceuticals and Personal Care Products in the Environment: What Are the Big Questions?, Environmental Health Perspectives, 120 (2012) 1221-1229. [40] M. Lillenberg, S. Yurchenko, K. Kipper, K. Herodes, V. Pihl, R. Lõhmus, M. Ivask, A. Kuu, S. Kutti, S.V. Litvin, L. Nei, Presence of fluoroquinolones and sulfonamides in urban sewage sludge and their degradation as a result of composting, International Journal of Environmental Science \& Technology, 7 (2010) 307-312.

[41] V.N. Kouloumbos, A. Schäffer, P.F.X. Corvini, Impact of sewage sludge conditioning and dewatering on the fate of nonylphenol in sludge-amended soils, Water Research, 42 (2008) 3941-3951.

[42] J.B. Quintana, S. Weiss, T. Reemtsma, Pathways and metabolites of microbial degradation of selected acidic pharmaceutical and their occurrence in municipal wastewater treated by a membrane bioreactor, Water Research, 39 (2005) 2654-2664.

[43] F.I. Hai, N. Tadkaew, J.A. McDonald, S.J. Khan, L.D. Nghiem, Is halogen content the most important factor in the removal of halogenated trace organics by MBR treatment?, Bioresource Technology, 102 (2011) 6299-6303.

[44] M. Barret, L. Delgadillo-Mirquez, E. Trably, N. Delgenes, F. Braun, G. Cea-Barcia, J.P. Steyer, D. Patureau, Anaerobic Removal of Trace Organic Contaminants in Sewage Sludge: 15 Years of Experience, Pedosphere, 22 (2012) 508-517. 
[45] K.C. Wijekoon, F.I. Hai, J. Kang, W.E. Price, W. Guo, H.H. Ngo, L.D. Nghiem, The fate of pharmaceuticals, steroid hormones, phytoestrogens, UV-filters and pesticides during MBR treatment, Bioresource Technology, 144 (2013) 247-254.

[46] D. Patureau, N. Delgenes, J.P. Delgenes, Impact of sewage sludge treatment processes on the removal of the endocrine disrupters nonylphenol ethoxylates, Chemosphere, 72 (2008) 586-591. [47] M. Lahti, A. Oikari, Microbial Transformation of Pharmaceuticals Naproxen, Bisoprolol, and Diclofenac in Aerobic and Anaerobic Environments, Archives of Environmental Contamination and Toxicology, 61 (2011) 202-210.

[48] M.T. García, E. Campos, I. Ribosa, A. Latorre, J. Sánchez-Leal, Anaerobic digestion of linear alkyl benzene sulfonates: Biodegradation kinetics and metabolite analysis, Chemosphere, 60 (2005) 16361643.

[49] S. Ramos, V. Homem, A. Alves, L. Santos, Advances in analytical methods and occurrence of organic UV-filters in the environment - A review, Science of The Total Environment, 526 (2015) 278-311.

[50] C. Chawla, S. Sarkar, S. Ali, L. Rehmann, G. Nakhla, M.B. Ray, Anaerobic digestibility of estrogens in wastewater sludge: Effect of ultrasonic pretreatment, Journal of Environmental Management, 145 (2014) 307-313.

[51] V.G. Samaras, A.S. Stasinakis, N.S. Thomaidis, D. Mamais, T.D. Lekkas, Fate of selected emerging micropollutants during mesophilic, thermophilic and temperature co-phased anaerobic digestion of sewage sludge, Bioresource Technology, 162 (2014) 365-372.

[52] L.N. Nguyen, F.I. Hai, W.E. Price, J. Kang, F.D.L. Leusch, F. Roddick, J.P. van de Merwe, S.F. Magram, L.D. Nghiem, Degradation of a broad spectrum of trace organic contaminants by an enzymatic membrane reactor: Complementary role of membrane retention and enzymatic degradation, International Biodeterioration \& Biodegradation, 99 (2015) 115-122.

[53] S. Barnabé, S.K. Brar, R.D. Tyagi, I. Beauchesne, R.Y. Surampalli, Pre-treatment and bioconversion of wastewater sludge to value-added products-Fate of endocrine disrupting compounds, Science of The Total Environment, 407 (2009) 1471-1488.

[54] M. Muller, F. Rabenoelina, P. Balaguer, D. Patureau, K. Lemenach, H. Budzinski, D. Barceló, M. López de Alda, M. Kuster, J.-P. Delgenès, G. Hernandez-Raquet, Chemical and biological analysis of endocrinedisrupting hormones and estrogenic activity in an advanced sewage treatment plant, Environmental Toxicology and Chemistry, 27 (2008) 1649-1658.

[55] W.O. Khunjar, S.A. Mackintosh, J. Skotnicka-Pitak, S. Baik, D.S. Aga, N.G. Love, Elucidating the Relative Roles of Ammonia Oxidizing and Heterotrophic Bacteria during the Biotransformation of $17 \alpha-$ Ethinylestradiol and Trimethoprim, Environmental Science \& Technology, 45 (2011) 3605-3612.

[56] N. Dorival-García, A. Zafra-Gómez, A. Navalón, J. González-López, E. Hontoria, J.L. Vílchez, Removal and degradation characteristics of quinolone antibiotics in laboratory-scale activated sludge reactors under aerobic, nitrifying and anoxic conditions, Journal of Environmental Management, 120 (2013) 7583.

[57] S. Larcher, V. Yargeau, Biodegradation of $17 \alpha$-ethinylestradiol by heterotrophic bacteria, Environmental Pollution, 173 (2013) 17-22.

[58] H.V. Phan, F.I. Hai, J. Kang, H.K. Dam, R. Zhang, W.E. Price, A. Broeckmann, L.D. Nghiem, Simultaneous nitrification/denitrification and trace organic contaminant (TrOC) removal by an anoxicaerobic membrane bioreactor (MBR), Bioresource Technology, 165 (2014) 96-104.

[59] L.B. Stadler, L. Su, C.J. Moline, A.S. Ernstoff, D.S. Aga, N.G. Love, Effect of redox conditions on pharmaceutical loss during biological wastewater treatment using sequencing batch reactors, Journal of Hazardous Materials, 282 (2015) 106-115.

[60] F.I. Hai, X. Li, W.E. Price, L.D. Nghiem, Removal of carbamazepine and sulfamethoxazole by MBR under anoxic and aerobic conditions, Bioresource Technology, 102 (2011) 10386-10390. 
[61] H.V. Phan, F.I. Hai, J.A. McDonald, R. Zhang, W.E. Price, A. Broeckmann, L.D. Nghiem, Nutrients and trace organic contaminants removal from wastewater of a resort town: Comparison between a pilot and a full scale membrane bioreactor, International Biodegradation and Biodeterioration, http://dx.doi.org/10.1016/j.ibiod.2015.2.010, (2015).

[62] A. Joss, H. Andersen, T. Ternes, P.R. Richle, H. Siegrist, Removal of Estrogens in Municipal Wastewater Treatment under Aerobic and Anaerobic Conditions: Consequences for Plant Optimization, Environmental Science \& Technology, 38 (2004) 3047-3055.

[63] G. Gasser, I. Pankratov, S. Elhanany, P. Werner, J. Gun, F. Gelman, O. Lev, Field and laboratory studies of the fate and enantiomeric enrichment of venlafaxine and O-desmethylvenlafaxine under aerobic and anaerobic conditions, Chemosphere, 88 (2012) 98-105.

[64] Z. Zhang, P. Gao, H. Su, P. Zhan, N. Ren, Y. Feng, Anaerobic biodegradation characteristics of estrone, estradiol, and $17 \alpha$-ethinylestradiol in activated sludge batch tests, Desalination and Water Treatment, 53 (2013) 985-993.

[65] L. Wang, K.C. Wijekoon, L.D. Nghiem, S.J. Khan, Removal of polycyclic musks by anaerobic membrane bioreactor: Biodegradation, biosorption, and enantioselectivity, Chemosphere, 117 (2014) 722-729.

[66] H. Hamid, C. Eskicioglu, Fate of estrogenic hormones in wastewater and sludge treatment: A review of properties and analytical detection techniques in sludge matrix, Water Research, 46 (2012) 58135833.

[67] S. Suárez, R. Reif, J.M. Lema, F. Omil, Mass balance of pharmaceutical and personal care products in a pilot-scale single-sludge system: Influence of T, SRT and recirculation ratio, Chemosphere, 89 (2012) 164-171.

[68] R.W. Gibson, M.-J. Wang, E. Padgett, J.M. Lopez-Real, A.J. Beck, Impact of drying and composting procedures on the concentrations of 4-nonylphenols, di-(2-ethylhexyl)phthalate and polychlorinated biphenyls in anaerobically digested sewage sludge, Chemosphere, 68 (2007) 1352-1358.

[69] M. Muñoz, M.F. Gomez-Rico, R. Font, PCDD/F and dioxin-like PCB concentrations during municipal solid waste biomethanation and subsequent composting, Chemosphere, 98 (2014) 73-77.

[70] A.L. Batt, S. Kim, D.S. Aga, Comparison of the occurrence of antibiotics in four full-scale wastewater treatment plants with varying designs and operations, Chemosphere, 68 (2007) 428-435.

[71] B. Styrishave, B. Halling-Sørensen, F. Ingerslev, Environmental risk assessment of three selective serotonin reuptake inhibitors in the aquatic environment: A case study including a cocktail scenario, Environmental Toxicology and Chemistry, 30 (2011) 254-261.

[72] P.V.L. Reddy, K.-H. Kim, A review of photochemical approaches for the treatment of a wide range of pesticides, Journal of Hazardous Materials, 285 (2015) 325-335.

[73] R. Salgado, R. Marques, J.P. Noronha, G. Carvalho, A. Oehmen, M.A.M. Reis, Assessing the removal of pharmaceuticals and personal care products in a full-scale activated sludge plant, Env Sci Poll Res Int, 19 (2012) 1818-1827.

[74] M. Clara, B. Strenn, E. Saracevic, N. Kreuzinger, Adsorption of bisphenol-A, 17 $\beta$-estradiole and 17 $\alpha-$ ethinylestradiole to sewage sludge, Chemosphere, 56 (2004) 843-851.

[75] M. Hörsing, A. Ledin, R. Grabic, J. Fick, M. Tysklind, J.I.C. Jansen, H.R. Andersen, Determination of sorption of seventy-five pharmaceuticals in sewage sludge, Water Research, 45 (2011) 4470-4482.

[76] N. Tadkaew, M. Sivakumar, S.J. Khan, J.A. McDonald, L.D. Nghiem, Effect of mixed liquor pH on the removal of trace organic contaminants in a membrane bioreactor, Bioresource Technology, 101 (2010) 1494-1500.

[77] B.Q. Liao, D.G. Allen, I.G. Droppo, G.G. Leppard, S.N. Liss, Surface properties of sludge and their role in bioflocculation and settleability, Water Research, 35 (2001) 339-350.

[78] B. Banihashemi, R.L. Droste, Sorption-desorption and biosorption of bisphenol A, triclosan, and $17 \alpha$-ethinylestradiol to sewage sludge, Science of The Total Environment, 487 (2014) 813-821. 
[79] W. Lee, S. Kang, H. Shin, Sludge characteristics and their contribution to microfiltration in submerged membrane bioreactors, Journal of Membrane Science, 216 (2003) 217-227.

[80] J.L. Tambosi, R.F. de Sena, M. Favier, W. Gebhardt, H.J. José, H.F. Schröder, R.d.F.P.M. Moreira, Removal of pharmaceutical compounds in membrane bioreactors (MBR) applying submerged membranes, Desalination, 261 (2010) 148-156.

[81] T.E.M. ten Hulscher, G. Cornelissen, Effect of temperature on sorption equilibrium and sorption kinetics of organic micropollutants - a review, Chemosphere, 32 (1996) 609-626.

[82] T.M. LaPara, A. Konopka, C.H. Nakatsu, J.E. Alleman, Thermophilic aerobic treatment of a synthetic wastewater in a membrane-coupled bioreactor, Journal of Industrial Microbiology and Biotechnology, 26 (2001) 203-209.

[83] Q. Zeng, Y. Li, G. Gu, Effect of Temperature on the Sorption of $17 \alpha$-ethinylestradiol to Aerobic and Anaerobic Sludges, in: Energy and Environment Technology, 2009. ICEET '09. International Conference on, 2009, pp. 294-297.

[84] F.I. Hai, K. Tessmer, L.N. Nguyen, J. Kang, W.E. Price, L.D. Nghiem, Removal of micropollutants by membrane bioreactor under temperature variation, Journal of Membrane Science, 383 (2011) 144-151. [85] K.C. Wijekoon, F.I. Hai, J. Kang, W.E. Price, W. Guo, H.H. Ngo, T.Y. Cath, L.D. Nghiem, A novel membrane distillation-thermophilic bioreactor system: Biological stability and trace organic compound removal, Bioresource Technology, 159 (2014) 334-341.

[86] L.N. Nguyen, F.I. Hai, J. Kang, L.D. Nghiem, W.E. Price, W. Guo, H.H. Ngo, K.-L. Tung, Comparison between sequential and simultaneous application of activated carbon with membrane bioreactor for trace organic contaminant removal, Bioresource Technology, 130 (2013) 412-417.

[87] F.I. Hai, K. Yamamoto, F. Nakajima, K. Fukushi, Application of a GAC-coated hollow fiber module to couple enzymatic degradation of dye on membrane to whole cell biodegradation within a membrane bioreactor, Journal of Membrane Science, 389 (2012) 67-75.

[88] G. Skouteris, D. Saroj, P. Melidis, F.I. Hai, S. Ouki, The Effect of Activated Carbon Addition on Membrane Bioreactor Processes for Wastewater Treatment and Reclamation - A Critical Review, Bioresource Technology, (2015) http://dx.doi.org/10.1016/j.biortech.2015.1003.1010.

[89] G.U. Semblante, S.D.R. Tampubolon, S.-J. You, Y.-F. Lin, T.-C. Chang, F.-C. Yen, Fouling reduction in membrane reactor through magnetic particles, Journal of Membrane Science, 435 (2013) 62-70.

[90] J.T. Alexander, F.I. Hai, T.M. Al-aboud, Chemical coagulation-based processes for trace organic contaminant removal: Current state and future potential, Journal of Environmental Management, 111 (2012) 195-207.

[91] F.I. Hai, K. Yamamoto, K. Fukushi, F. Nakajima, Fouling resistant compact hollow-fiber module with spacer for submerged membrane bioreactor treating high strength industrial wastewater, Journal of Membrane Science, 317 (2008) 34-42.

[92] M. Auriol, Y. Filali-Meknassi, R.D. Tyagi, C.D. Adams, R.Y. Surampalli, Endocrine disrupting compounds removal from wastewater, a new challenge, Process Biochemistry, 41 (2006) 525-539.

[93] F. Li, A. Yuasa, A. Obara, A.P. Mathews, Aerobic batch degradation of 17- $\beta$ estradiol (E2) by activated sludge: Effects of spiking E2 concentrations, MLVSS and temperatures, Water Research, 39 (2005) 2065-2075.

[94] F.P. Shariati, M.R. Mehrnia, B.M. Salmasi, M. Heran, C. Wisniewski, M.H. Sarrafzadeh, Membrane bioreactor for treatment of pharmaceutical wastewater containing acetaminophen, Desalination, 250 (2010) 798-800.

[95] X. Li, F.I. Hai, N. Tadkaew, S. Gilbertson, L.D. Nghiem, Strategies to enhance the removal of the persistent pharmaceutically active compound carbamazepine by membrane bioreactors Desalination and Water Treatment, 34 (2011) 402-407. 
[96] F. I. Hai, T. Riley, S. Shawkat, S. Magram, K. Yamamoto, Removal of Pathogens by Membrane Bioreactors: A Review of the Mechanisms, Influencing Factors and Reduction in Chemical Disinfectant Dosing, Water, 6 (2014) 3603.

[97] E.J. Marti, J.R. Batista, Impact of secondary treatment types and sludge handling processes on estrogen concentration in wastewater sludge, Science of The Total Environment, 470-471 (2014) 10561067.

[98] M. Esperanza, M.T. Suidan, R. Marfil-Vega, C. Gonzalez, G.A. Sorial, P. McCauley, R. Brenner, Fate of sex hormones in two pilot-scale municipal wastewater treatment plants: Conventional treatment, Chemosphere, 66 (2007) 1535-1544.

[99] R.D. Holbrook, J.T. Novak, T.J. Grizzard, N.G. Love, Estrogen Receptor Agonist Fate during Wastewater and Biosolids Treatment Processes: A Mass Balance Analysis, Environmental Science \& Technology, 36 (2002) 4533-4539.

[100] S. Ömeroğlu, F.D. Sanin, Fate and degradation kinetics of nonylphenol compounds in aerobic batch digesters, Water Research, 64 (2014) 1-12.

[101] E. Trably, D. Patureau, Successful Treatment of Low PAH-Contaminated Sewage Sludge in Aerobic Bioreactors Environmental Science and Pollution Research, 13 (2006) 170-176.

[102] W. Gao, B.C. Liao, F.I. Hai, Anaerobic MBRs, in: F.I. Hai, K. Yamamoto, C.H. Lee (Eds.) Membrane Biological Reactors, IWA Publishing, UK, 2014, pp. 335-377.

[103] L.D. Nghiem, T.T. Nguyen, P. Manassa, S.K. Fitzgerald, M. Dawson, S. Vierboom, Co-digestion of sewage sludge and crude glycerol for on-demand biogas production, International Biodeterioration \& Biodegradation, 95, Part A (2014) 160-166.

[104] L.D. Nghiem, P. Manassa, M. Dawson, S.K. Fitzgerald, Oxidation reduction potential as a parameter to regulate micro-oxygen injection into anaerobic digester for reducing hydrogen sulphide concentration in biogas, Bioresource Technology, 173 (2014) 443-447.

[105] Y. Chen, J.J. Cheng, K.S. Creamer, Inhibition of anaerobic digestion process: A review, Bioresource Technology, 99 (2008) 4044-4064.

[106] M. Narumiya, N. Nakada, N. Yamashita, H. Tanaka, Phase distribution and removal of pharmaceuticals and personal care products during anaerobic sludge digestion, Journal of Hazardous Materials, 260 (2013) 305-312.

[107] E.M. Golet, I. Xifra, H. Siegrist, A.C. Alder, W. Giger, Environmental exposure assessment of fluoroquinolone antibacterial agents from sewage to soil, Environmental Science and Technology, 37 (2003) 3243-3249.

[108] J.L. Sanz, E. Culubret, J. De Ferrer, A. Moreno, J.L. Berna, Anaerobic biodegradation of linear alkylbenzene sulfonate (LAS) in upflow anaerobic sludge blanket (UASB) reactors, Biodegradation, 14 (2003) 57-64.

[109] M. Carballa, F. Omil, T. Ternes, J.M. Lema, Fate of pharmaceutical and personal care products (PPCPs) during anaerobic digestion of sewage sludge, Water Research, 41 (2007) 2139-2150.

[110] S. Combalbert, V. Bellet, P. Dabert, N. Bernet, P. Balaguer, G. Hernandez-Raquet, Fate of steroid hormones and endocrine activities in swine manure disposal and treatment facilities, Water Research, 46 (2012) 895-906.

[111] H. Zhang, J. Shi, X. Liu, X. Zhan, Q. Chen, Occurrence and removal of free estrogens, conjugated estrogens, and bisphenol A in manure treatment facilities in East China, Water Research, 58 (2014) 248257.

[112] D. Massé, N. Saady, Y. Gilbert, Potential of Biological Processes to Eliminate Antibiotics in Livestock Manure: An Overview, Animals, 4 (2014) 146-163.

[113] M.S. de Graaff, N.M. Vieno, K. Kujawa-Roeleveld, G. Zeeman, H. Temmink, C.J.N. Buisman, Fate of hormones and pharmaceuticals during combined anaerobic treatment and nitrogen removal by partial nitritation-anammox in vacuum collected black water, Water Research, 45 (2011) 375-383. 
[114] H. Zhou, Q. Zhang, L. Ma, B. Tu, H. Li, Y. Zhou, Removal of clofibric acid and diclofenac during anaerobic digestion of sewage sludge, Environment Protection Engineering, 39 (2013) 63-77.

[115] T.A. Ogunyoku, T.M. Young, Removal of triclocarban and triclosan during municipal biosolid production, Water Environment Research, 86 (2014) 197-203.

[116] M. Muller, S. Combalbert, N. Delgenès, V. Bergheaud, V. Rocher, P. Benoît, J.-P. Delgenès, D. Patureau, G. Hernandez-Raquet, Occurrence of estrogens in sewage sludge and their fate during plantscale anaerobic digestion, Chemosphere, 81 (2010) 65-71.

[117] I. Limam, M. Mezni, A. Guenne, C. Madigou, M.R. Driss, T. Bouchez, L. Mazéas, Evaluation of biodegradability of phenol and bisphenol A during mesophilic and thermophilic municipal solid waste anaerobic digestion using 13C-labeled contaminants, Chemosphere, 90 (2013) 512-520.

[118] C. Reyes-Contreras, V. Matamoros, I. Ruiz, M. Soto, J.M. Bayona, Evaluation of PPCPs removal in a combined anaerobic digester-constructed wetland pilot plant treating urban wastewater, Chemosphere, 84 (2011) 1200-1207.

[119] N. Paterakis, T.Y. Chiu, Y.K.K. Koh, J.N. Lester, E.J. McAdam, M.D. Scrimshaw, A. Soares, E. Cartmell, The effectiveness of anaerobic digestion in removing estrogens and nonylphenol ethoxylates, Journal of Hazardous Materials, 199-200 (2012) 88-95.

[120] E. Trably, D. Patureau, J.P. Delgenes, Enhancement of polycyclic aromatic hydrocarbons removal during anaerobic treatment of urban sludge, in, 2003, pp. 53-60.

[121] T. Benabdallah El-Hadj, J. Dosta, R. Márquez-Serrano, J. Mata-Álvarez, Effect of ultrasound pretreatment in mesophilic and thermophilic anaerobic digestion with emphasis on naphthalene and pyrene removal, Water Research, 41 (2007) 87-94.

[122] M. Carballa, F. Omil, A.C. Alder, J.M. Lema, Comparison between the conventional anaerobic digestion of sewage sludge and its combination with a chemical or thermal pre-treatment concerning the removal of pharmaceuticals and personal care products, in: Water Science and Technology, 2006, pp. 109-117.

[123] H. Hamid, C. Eskicioglu, Effect of microwave hydrolysis on transformation of steroidal hormones during anaerobic digestion of municipal sludge cake, Water Research, 47 (2013) 4966-4977.

[124] P. Ivashechkin, P.F.X. Corvini, M. Dohmann, Behaviour of endocrine disrupting chemicals during the treatment of municipal sewage sludge, in: Water Science and Technology, 2004, pp. 133-140.

[125] M. Kim, P. Guerra, M. Theocharides, K. Barclay, S.A. Smyth, M. Alaee, Polybrominated diphenyl ethers in sewage sludge and treated biosolids: Effect factors and mass balance, Water Research, 47 (2013) 6496-6505.

[126] H. Li, Y. Jin, Y. Nie, Application of alkaline treatment for sludge decrement and humic acid recovery, Bioresource Technology, 100 (2009) 6278-6283.

[127] T. Vasskog, O. Bergersen, T. Anderssen, E. Jensen, T. Eggen, Depletion of selective serotonin reuptake inhibitors during sewage sludge composting, Waste Management, 29 (2009) 2808-2815. [128] J. Martín, J.L. Santos, I. Aparicio, E. Alonso, Pharmaceutically active compounds in sludge stabilization treatments: Anaerobic and aerobic digestion, wastewater stabilization ponds and composting, Science of The Total Environment, 503-504 (2015) 97-104.

[129] P. Oleszczuk, Influence of different bulking agents on the disappearance of polycyclic aromatic hydrocarbons (PAHs) during sewage sludge composting, Water, Air, and Soil Pollution, 175 (2006) 15-32. [130] K. Xia, A. Bhandari, K. Das, G. Pillar, Occurrence and fate of pharmaceuticals and personal care products (PPCPs) in biosolids, Journal of Environmental Quality, 34 (2005) 91-104.

[131] J. Moeller, U. Reeh, Degradation of Nonylphenol Ethoxylates (NPE) in Sewage Sludge and Source Separated Municipal Solid Waste Under Bench-Scale Composting Conditions, Bulletin of Environmental Contamination and Toxicology, 70 (2003) 0248-0254.

[132] C. Pakou, M. Kornaros, K. Stamatelatou, G. Lyberatos, On the fate of LAS, NPEOs and DEHP in municipal sewage sludge during composting, Bioresource Technology, 100 (2009) 1634-1642. 
[133] E. Sanz, D. Prats, M. Rodríguez, A. Camacho, Effect of temperature and organic nutrients on the biodegradation of linear alkylbenzene sulfonate (LAS) during the composting of anaerobically digested sludge from a wastewater treatment plant, Waste Management, 26 (2006) 1237-1245.

[134] S.K. Marttinen, K. Hänninen, J.A. Rintala, Removal of DEHP in composting and aeration of sewage sludge, Chemosphere, 54 (2004) 265-272.

[135] K.C. Das, K. Xia, Transformation of 4-nonylphenol isomers during biosolids composting, Chemosphere, 70 (2008) 761-768.

[136] D. Patureau, N. Delgenes, M. Muller, S. Dagnino, C. Lhoutellier, J.-P. Delgenes, P. Balaguer, G. Hernandez-Raquet, Chemical and toxicological assessment of a full-scale biosolid compost, Environmental Toxicology and Chemistry, 31 (2012) 2748-2756.

[137] Y. Sadef, T.G. Poulsen, K. Bester, Impact of compost process temperature on organic micropollutant degradation, Science of The Total Environment, 494-495 (2014) 306-312.

[138] O. Braga, G.A. Smythe, A.I. Schäfer, A.J. Feitz, Fate of steroid estrogens in Australian inland and coastal wastewater treatment plants, Environmental Science and Technology, 39 (2005) 3351-3358.

[139] A. Bernal-Martinez, H. Carrère, D. Patureau, J.-P. Delgenès, Ozone pre-treatment as improver of PAH removal during anaerobic digestion of urban sludge, Chemosphere, 68 (2007) 1013-1019.

[140] J. Lahnsteiner, R. Vranitzky, Ozone treatment of organic micro-pollutants in sewage sludge, Water Science and Technology, 61 (2010) 2923-2930.

[141] Z. Qiang, Y. Nie, W. Ben, J. Qu, H. Zhang, Degradation of endocrine-disrupting chemicals during activated sludge reduction by ozone, Chemosphere, 91 (2013) 366-373.

[142] V. Flotron, C. Delteil, Y. Padellec, V. Camel, Removal of sorbed polycyclic aromatic hydrocarbons from soil, sludge and sediment samples using the Fenton's reagent process, Chemosphere, 59 (2005) 1427-1437.

[143] X.-J. Zheng, J.-F. Blais, G. Mercier, M. Bergeron, P. Drogui, PAH removal from spiked municipal wastewater sewage sludge using biological, chemical and electrochemical treatments, Chemosphere, 68 (2007) 1143-1152.

[144] Y. Li, A. Zhang, Removal of steroid estrogens from waste activated sludge using Fenton oxidation: Influencing factors and degradation intermediates, Chemosphere, 105 (2014) 24-30.

[145] T.T.H. Pham, R.D. Tyagi, S.K. Brar, R.Y. Surampalli, Effect of ultrasonication and Fenton oxidation on biodegradation of bis(2-ethylhexyl) phthalate (DEHP) in wastewater sludge, Chemosphere, 82 (2011) 923-928.

[146] N.K. Salihoglu, G. Karaca, G. Salihoglu, Y. Tasdemir, Removal of polycyclic aromatic hydrocarbons from municipal sludge using UV light, Desalination and Water Treatment, 44 (2012) 324-333.

[147] O.S. Keen, S. Baik, K.G. Linden, D.S. Aga, N.G. Love, Enhanced Biodegradation of Carbamazepine after UV/H2O2 Advanced Oxidation, Environmental Science \& Technology, 46 (2012) 6222-6227.

[148] B.V. Chang, T.H. Wang, S.Y. Yuan, Biodegradation of four phthalate esters in sludge, Chemosphere, 69 (2007) 1116-1123.

[149] P.J. McNamara, C.A. Wilson, M.T. Wogen, S.N. Murthy, J.T. Novak, P.J. Novak, The effect of thermal hydrolysis pretreatment on the anaerobic degradation of nonylphenol and short-chain nonylphenol ethoxylates in digested biosolids, Water Research, 46 (2012) 2937-2946.

[150] G. Karaca, S.S. Cindoruk, Y. Tasdemir, Migration of polycyclic aromatic hydrocarbons (PAHs) in urban treatment sludge to the air during PAH removal applications, Journal of the Air \& Waste Management Association, 64 (2013) 568-577.

[151] S.B. Larsen, D. Karakashev, I. Angelidaki, J.E. Schmidt, Ex-situ bioremediation of polycyclic aromatic hydrocarbons in sewage sludge, Journal of Hazardous Materials, 164 (2009) 1568-1572.

[152] N. Boon, J. Goris, P. De Vos, W. Verstraete, E.M. Top, Bioaugmentation of Activated Sludge by an Indigenous 3-Chloroaniline-Degrading Comamonas testosteroni Strain, I2gfp, Applied and Environmental Microbiology, 66 (2000) 2906-2913. 
[153] A.-L. Hesham, S. Khan, Y. Tao, D. Li, Y. Zhang, M. Yang, Biodegradation of high molecular weight PAHs using isolated yeast mixtures: application of meta-genomic methods for community structure analyses, Environmental Science and Pollution Research, 19 (2012) 3568-3578.

[154] M.J. García-Galán, C.E. Rodríguez-Rodríguez, T. Vicent, G. Caminal, M.S. Díaz-Cruz, D. Barceló, Biodegradation of sulfamethazine by Trametes versicolor: Removal from sewage sludge and identification of intermediate products by UPLC-QqTOF-MS, Science of The Total Environment, 409 (2011) 5505-5512.

[155] C.E. Rodríguez-Rodríguez, A. Jelić, M.A. Pereira, D.Z. Sousa, M. Petrović, M.M. Alves, D. Barceló, G. Caminal, T. Vicent, Bioaugmentation of Sewage Sludge with Trametes versicolor in Solid-Phase Biopiles Produces Degradation of Pharmaceuticals and Affects Microbial Communities, Environmental Science \& Technology, 46 (2012) 12012-12020.

[156] M. Badia-Fabregat, C.E. Rodríguez-Rodríguez, P. Gago-Ferrero, A. Olivares, B. Piña, M.S. Díaz-Cruz, T. Vicent, D. Barceló, G. Caminal, Degradation of UV filters in sewage sludge and 4-MBC in liquid medium by the ligninolytic fungus Trametes versicolor, Journal of Environmental Management, 104 (2012) 114120.

[157] C.E. Rodríguez-Rodríguez, D. Lucas, E. Barón, P. Gago-Ferrero, D. Molins-Delgado, S. RodríguezMozaz, E. Eljarrat, M. Silvia Díaz-Cruz, D. Barceló, G. Caminal, T. Vicent, Re-inoculation strategies enhance the degradation of emerging pollutants in fungal bioaugmentation of sewage sludge, Bioresource Technology, 168 (2014) 180-189.

[158] L.N. Nguyen, F.I. Hai, S. Yang, J. Kang, F.D.L. Leusch, F. Roddick, W.E. Price, L.D. Nghiem, Removal of trace organic contaminants by an MBR comprising a mixed culture of bacteria and white-rot fungi, Bioresource Technology, 148 (2013) 234-241.

[159] F.I. Hai, O. Modin, K. Yamamoto, K. Fukushi, F. Nakajima, L.D. Nghiem, Pesticide removal by a mixed culture of bacteria and white-rot fungi, Journal of the Taiwan Institute of Chemical Engineers, 43 (2012) 459-462.

[160] S. Yang, F.I. Hai, L.D. Nghiem, W.E. Price, F. Roddick, M.T. Moreira, S.F. Magram, Understanding the factors controlling the removal of trace organic contaminants by white-rot fungi and their lignin modifying enzymes: A critical review, Bioresource Technology, 141 (2013) 97-108. 


\section{LIST OF FIGURES}

Figure 1 Schematic diagram depicting the key operation conditions impacting the accumulation of TrOCs on activated sludge

Figure 2 TrOC removal by anaerobic digestion superimposed with $\log \mathrm{D}$ at $\mathrm{pH}$ 7. Error bars represent variation in removal efficiencies reported by different independent studies ( $\mathrm{n}=$ number of samples): $17 \alpha$ ethinylestradiol (3), bisoprolol (1), bisphenol A (2), carbamazepine (4), clofibric acid (1), diazepam (2), diclofenac (4), estriol (4), estrone (4), galaxolide (2), ibuprofen (2), iopromide (2), ketoprofen (3), naproxen (3), roxithromycin (2), sulfamethoxazole (2), triclocarban (2), triclosan (4). Data source: [8, 47, $51,98,106,109,113-119]$

Figure 3 TrOC removal by mesophilic and thermophilic anaerobic digestion. Error bars represent variation in removal efficiencies reported by different independent studies $((n, m)=$ number of samples in $\mathrm{m}$ mesophilic and, $\mathrm{n}$ thermophilic condition, respectively): $17 \beta$-estradiol $(4,2)$, estriol $(4,2)$, estrone $(4$, $2)$, ibuprofen $(2,2)$, naproxen $(3,2)$, nonylphenol $(3,3)$, nonylphenol monoethoxylate $(3,3))$. Data source: $[8,47,51,98,116,119]$ 


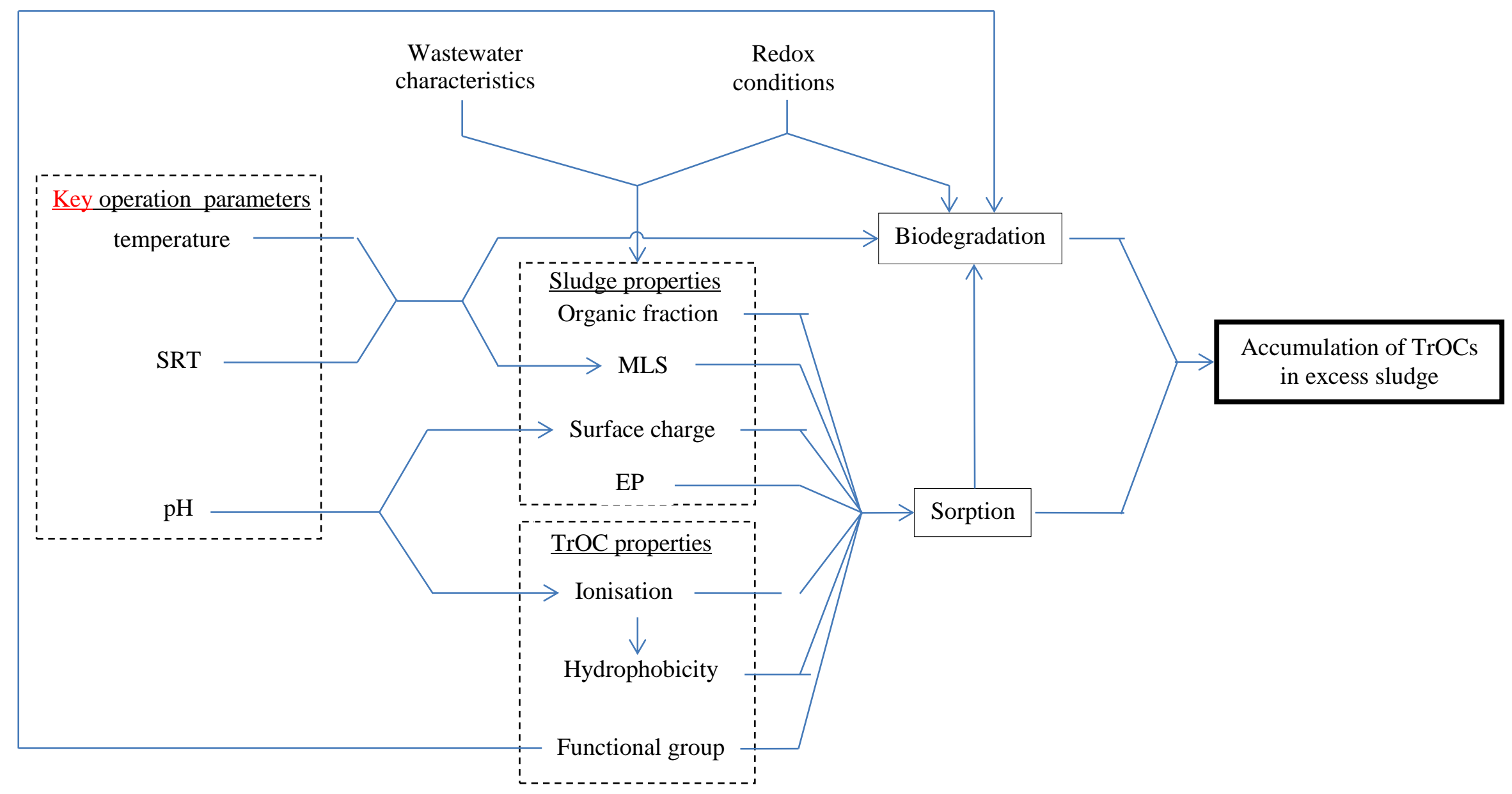

Figure 1 Schematic diagram depicting the key operation conditions impacting the accumulation of TrOCs on activated sludge 


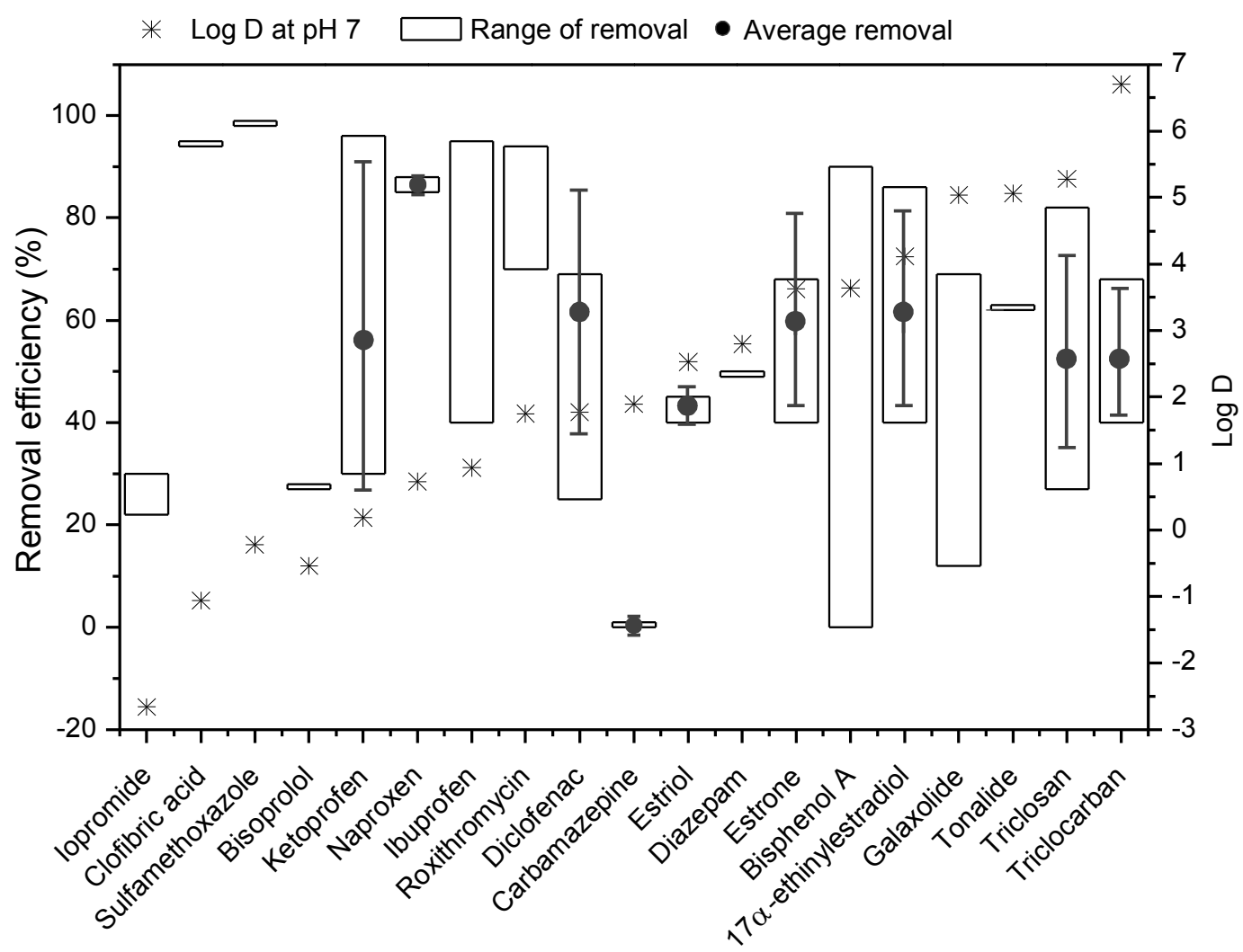

Figure 2 TrOC removal by anaerobic digestion superimposed with $\log \mathrm{D}$ at $\mathrm{pH} 7$. Error bars represent variation in removal efficiencies reported by different independent studies $(\mathrm{n}=$ number of samples): 17 $\alpha$-ethinylestradiol (3), bisoprolol (1), bisphenol A (2), carbamazepine (4), clofibric acid (1), diazepam (2), diclofenac (4), estriol (4), estrone (4), galaxolide (2), ibuprofen (2), iopromide (2), ketoprofen (3), naproxen (3), roxithromycin (2), sulfamethoxazole (2), triclocarban (2), triclosan (4). Data source: [8, 47, 51, 98, 106, 109, 113-119] 


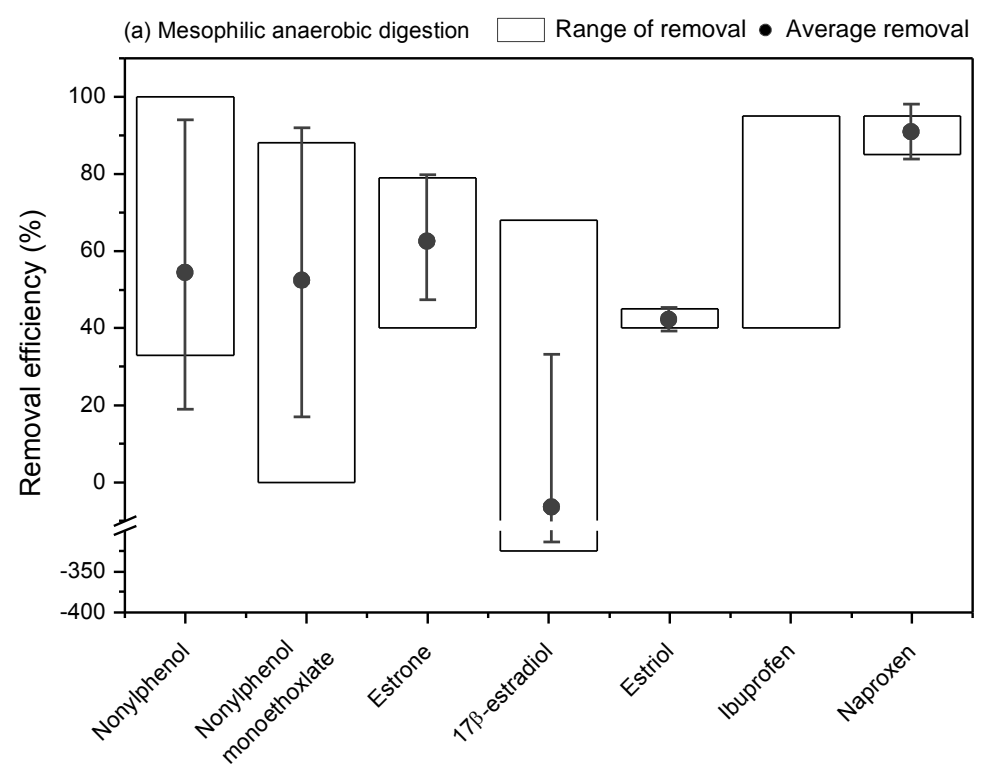

(b) Thermophilic anaerobic digestion $\square$ Range of removal $\bullet$ Average removal

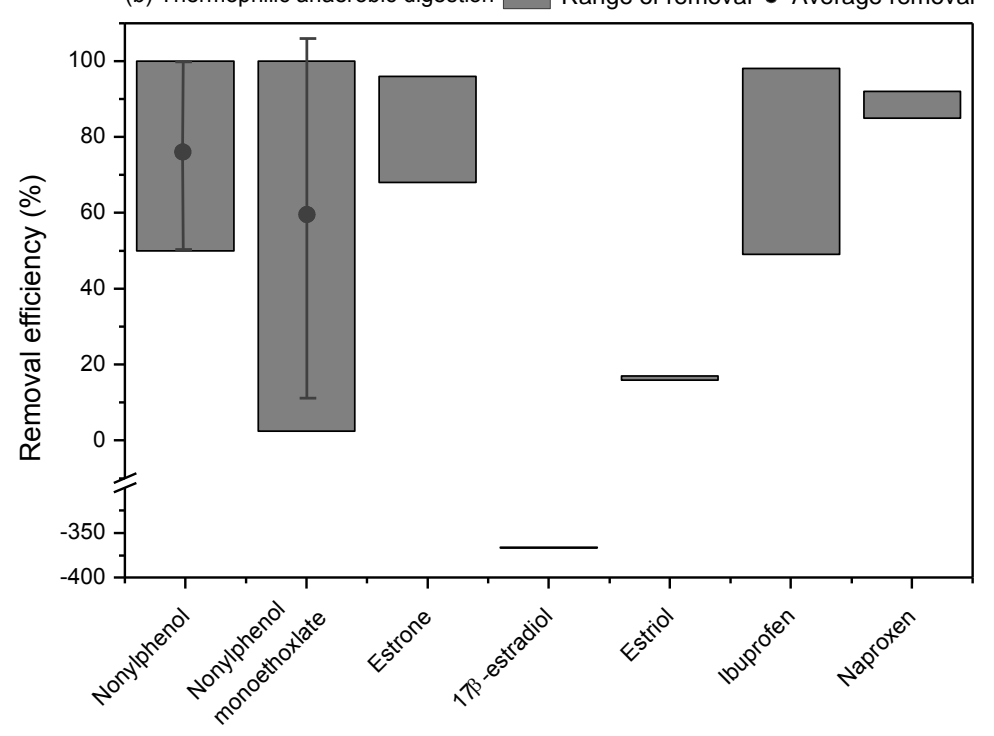

Figure 3 TrOC removal by mesophilic and thermophilic anaerobic digestion. Error bars represent variation in removal efficiencies reported by different independent studies $((\mathrm{n}, \mathrm{m})=$ number of samples in m mesophilic and, $n$ thermophilic condition, respectively): $17 \beta-$ estradiol $(4,2)$, estriol $(4,2)$, estrone $(4,2)$, ibuprofen $(2,2)$, naproxen $(3,2)$, nonylphenol $(3$, 3), nonylphenol monoethoxylate (3, 3). Data source: $[8,47,51,98,116,119]$ 


\section{LIST OF TABLES}

Table 1 TrOC removal efficiency at different composting conditions.

Table 2 TrOC removal efficiency of advanced oxidation treatment of sludge.

Table 3 Sludge treatment by bioagumentation with different microorganisms 
Table 1 TrOC removal efficiency at different composting conditions.

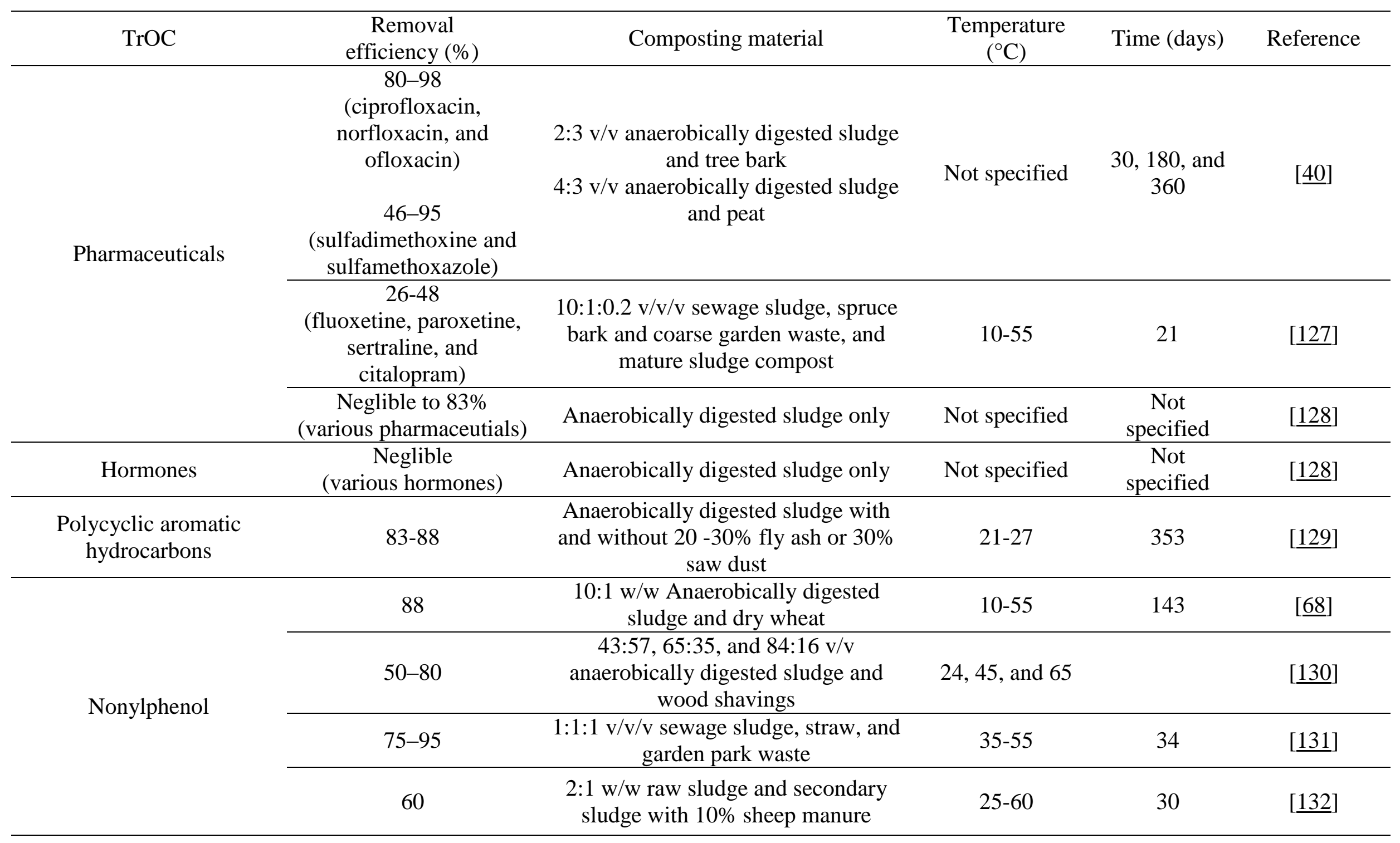




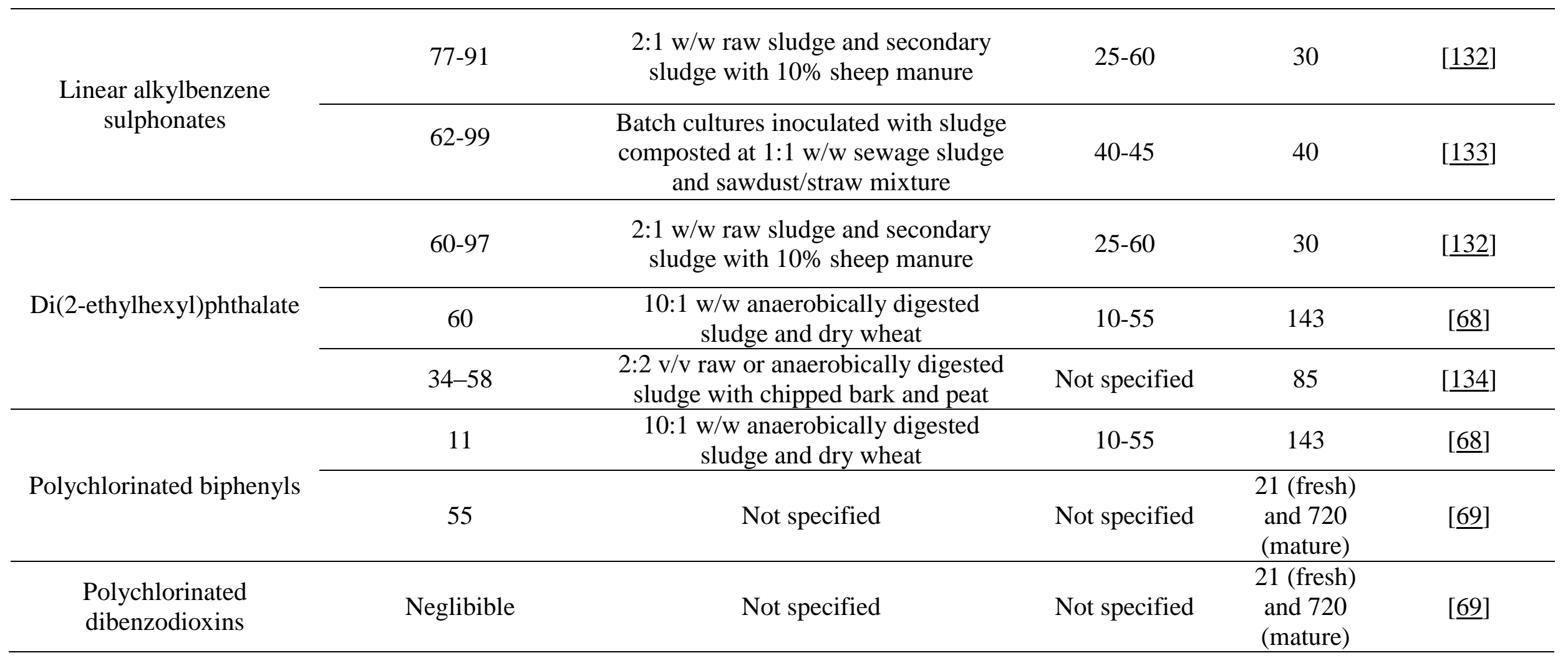


Table 2 TrOC removal efficiency of advanced oxidation treatment of sludge.

\begin{tabular}{|c|c|c|c|c|c|}
\hline Treatment & $\begin{array}{c}\text { Treatment } \\
\text { configuration }\end{array}$ & Treatment conditions & $\mathrm{TrOC} / \mathrm{s}$ & $\begin{array}{l}\text { Effect on TrOC } \\
\text { removal }\end{array}$ & Reference \\
\hline \multirow{5}{*}{ Ozonation } & $\begin{array}{l}\text { Pre-treatment to } \\
\text { anaerobic digester }\end{array}$ & $\begin{array}{l}\text { Ozone dosage }=0.1 \mathrm{~g} \mathrm{O}_{3} \\
\text { g/total solids (TS) }\end{array}$ & $\begin{array}{l}\text { Polycyclic aromatic } \\
\text { hydrocarbons }\end{array}$ & $\begin{array}{l}\text { Pre-ozonation increased } \\
\text { the TrOC removal by } \\
\text { anaerobic digestion } \\
\text { from about } 25 \text { to } 50 \%\end{array}$ & [139] \\
\hline & Sludge treatment & $\begin{array}{c}\text { Ozone dosage }=0.021-0.081 \\
\text { g O3/g TS }\end{array}$ & $\begin{array}{l}\text { Polycyclic aromatic } \\
\text { hydrocarbons }\end{array}$ & $\begin{array}{l}\text { Resulted to } 18-60 \% \\
\text { polycylic hydrocarbon } \\
\text { removal from sludge }\end{array}$ & [140] \\
\hline & Sludge treatment & $\begin{array}{c}\text { Ozone dosage }=0.1 \mathrm{~g} \mathrm{O}_{3} \\
\text { g/TS }\end{array}$ & $\begin{array}{c}\text { Estrone, estradiol, estriol, } \\
17 \alpha \text {-ethinylestradiol, } \\
\text { bisphenol A, and } \\
\text { nonylphenol }\end{array}$ & 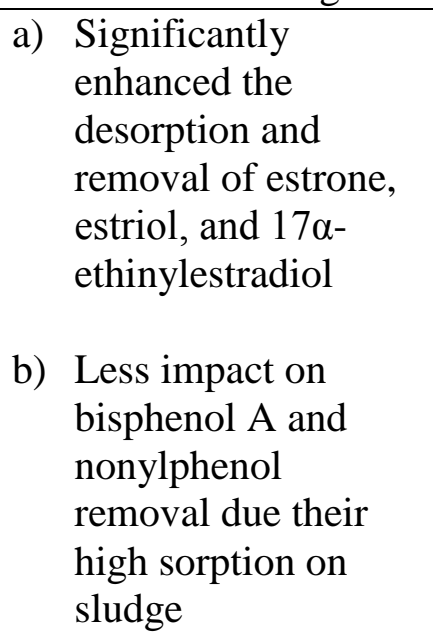 & {$[141]$} \\
\hline & \multirow[t]{2}{*}{$\begin{array}{l}\text { Pre-treatment to } \\
\text { anaerobic digester }\end{array}$} & \multirow[t]{2}{*}{$\begin{array}{c}\text { Ozone dosage }=0.02 \mathrm{~g} \mathrm{O}_{3} / \mathrm{g} \\
\text { TS }\end{array}$} & \multirow[t]{2}{*}{$\begin{array}{l}\text { Various pharmaceuticals } \\
\text { and hormones }\end{array}$} & $\begin{array}{l}\text { a) Only } \\
\text { carbamazepine was } \\
\text { amenable to } \\
\text { ozonation }\end{array}$ & [8] \\
\hline & & & & $\begin{array}{l}\text { b) The removal of } \\
\text { other } \\
\text { pharmaceuticals and }\end{array}$ & \\
\hline
\end{tabular}




\begin{tabular}{|c|c|c|c|c|c|}
\hline & & & & $\begin{array}{l}\text { hormones in } \\
\text { anaerobic digestion } \\
\text { were not affected by } \\
\text { ozonation }\end{array}$ & \\
\hline \multirow{4}{*}{ Fenton treatment } & Sludge treatment & $\begin{array}{c}4.9 \mathrm{~mol} / \mathrm{L} \mathrm{H}_{2} \mathrm{O}_{2} \text { and } 0.1 \\
\mathrm{~mol} / \mathrm{L} \mathrm{Fe}^{2+}\end{array}$ & $\begin{array}{c}\text { Polycyclic aromatic } \\
\text { hydrocarbons }\end{array}$ & $\begin{array}{l}\text { Resulted to } 38-67 \% \\
\text { removal from sludge }\end{array}$ & {$[142]$} \\
\hline & Sludge treatment & $\begin{array}{c}3 \% \text { by volume } \mathrm{H}_{2} \mathrm{O}_{2} \text { and } \\
11 \% \text { by weight } \mathrm{Fe}^{2+} \\
\text { adjusted to pH } 2 \text { or } 4\end{array}$ & $\begin{array}{l}\text { Polycyclic aromatic } \\
\text { hydrocarbons }\end{array}$ & $\begin{array}{l}\text { Decreasing } \mathrm{pH} \text { from } 4 \\
\text { to } 2 \text { increased } \\
\text { polycyclic aromatic } \\
\text { hydrocarbon removal } \\
\text { form sludge from } 20 \text { to } \\
30 \%\end{array}$ & [143] \\
\hline & Sludge treatment & $\begin{array}{l}15.62 \mathrm{mmol} \mathrm{g}^{-1} \mathrm{H}_{2} \mathrm{O}_{2} \\
0.167 \mathrm{Fe}^{2+} \text {-to- } \mathrm{H}_{2} \mathrm{O}_{2} \text { molar } \\
\text { ratio, adjusted to } \mathrm{pH} 3\end{array}$ & Various hormones & $\begin{array}{l}\text { Resulted to } 70-98 \% \\
\text { removal of various } \\
\text { hormones }\end{array}$ & {$[144]$} \\
\hline & $\begin{array}{l}\text { Pre-treatment to } \\
\text { aerobic digestion }\end{array}$ & $\begin{array}{c}0.01 \mathrm{~mL} \mathrm{H}_{2} \mathrm{O}_{2} / g \mathrm{SS} \text { and } \\
150\left[\mathrm{H}_{2} \mathrm{O}_{2}\right]_{0} /\left[\mathrm{Fe}^{2+}\right]_{0} \text { at } 36 \\
{ }^{\circ} \mathrm{C}\end{array}$ & Di(2-ethylhexyl)phthalate & $\begin{array}{l}\text { Increased di(2- } \\
\text { ethylhexyl)phthalate } \\
\text { removal of aerobic } \\
\text { digestion from } 72 \text { to } \\
85 \%\end{array}$ & [145] \\
\hline UV oxidation & Sludge treatment & $\begin{array}{c}\text { Sludge treated under three } \\
24-\mathrm{W} \text { UV lamps }(\lambda=254 \\
\mathrm{nm}) \text { at } 36^{\circ} \mathrm{C}\end{array}$ & $\begin{array}{l}\text { Polycyclic aromatic } \\
\text { hydrocarbons }\end{array}$ & $\begin{array}{l}\text { Resulted to } 15 \% \\
\text { polycyclic aromatic } \\
\text { hydrocarbon removal }\end{array}$ & [146] \\
\hline $\mathrm{UV} / \mathrm{TiO}_{2}$ oxidation & Sludge treatment & $\begin{array}{c}\text { Sludge with } 0.5 \text { and } 20 \% \\
\text { by weight } \mathrm{TiO}_{2} \text { (Degussa } \\
\mathrm{P} 25) \text { treated under three } \\
24-\mathrm{W} \text { UV lamps }(\lambda=254 \\
\text { nm) at } 36^{\circ} \mathrm{C}\end{array}$ & $\begin{array}{l}\text { Polycyclic aromatic } \\
\text { hydrocarbons }\end{array}$ & $\begin{array}{l}\text { Resulted to } 21-63 \% \\
\text { polycyclic aromatic } \\
\text { hydrocarbon removal }\end{array}$ & {$[146]$} \\
\hline $\mathrm{UV} / \mathrm{H}_{2} \mathrm{O}_{2}$ oxidation & Sludge treatment & $\begin{array}{c}\text { Sludge treated under UV } \\
(\lambda=253.7 \mathrm{~nm}) \text { at the rate of } \\
0.069 \mathrm{~mW} / \mathrm{cm}^{2} \text { and } 0.5 \\
\mathrm{~mol} / \mathrm{L} \mathrm{H}_{2} \mathrm{O}_{2}\end{array}$ & $\begin{array}{c}\text { Estrone, estradiol, estriol, } \\
17 \alpha \text {-ethinylestradiol, and } \\
\text { bisphenol A }\end{array}$ & $\begin{array}{l}\text { Resulted to } 67-97 \% \\
\text { removal of bisphenol A } \\
\text { and various hormones }\end{array}$ & [9] \\
\hline
\end{tabular}




\begin{tabular}{|c|c|c|c|c|c|}
\hline & Sludge treatment & $\begin{array}{l}\mathrm{UV} \text { treatment }(\lambda=254 \mathrm{~nm}) \\
\text { at the rate of } 3.0 \mathrm{~mW} / \mathrm{cm}^{2} \\
\text { and } 0.5 \mathrm{~mol} / \mathrm{L} \mathrm{H}_{2} \mathrm{O}_{2}\end{array}$ & Carbamazepine & $\begin{array}{l}\text { Increased batch } \\
\text { carbamazepine removal } \\
\text { by } 45 \%\end{array}$ & [147] \\
\hline \multirow{4}{*}{ Ultrasonication } & $\begin{array}{l}\text { Pre-treatment to } \\
\text { anaerobic } \\
\text { digestion }\end{array}$ & $\begin{array}{c}\text { Ultrasonication at } 11,000 \\
\mathrm{~kJ} / \mathrm{kg} \text { TS }\end{array}$ & Napthalene & $\begin{array}{l}\text { Increased naphthalene } \\
\text { removal of anaerobic } \\
\text { digestion from } 34-50 \text { to } \\
54-65 \%\end{array}$ & [121] \\
\hline & $\begin{array}{l}\text { Pre-treatment to } \\
\text { anaerobic } \\
\text { digestion }\end{array}$ & $\begin{array}{c}\text { Ultrasonication at } 3,000 \\
\mathrm{~kJ} / \mathrm{L}\end{array}$ & Estrone & $\begin{array}{l}\text { Increased the aqueous } \\
\text { concentration of estrone } \\
\text { in the anaerobic } \\
\text { digester }\end{array}$ & [50] \\
\hline & $\begin{array}{l}\text { Pre-treatment to a } \\
\text { batch aerobic } \\
\text { reactor }\end{array}$ & $\begin{array}{l}\text { Ultrasonication at } 20 \mathrm{kHz} \\
\text { and } 0.1-0.2 \mathrm{~W} / \mathrm{ml} \text { for } 10-40 \\
\mathrm{~min}\end{array}$ & Phthalate esters & $\begin{array}{l}\text { Decreased half-lives of } \\
\text { phthalate esters by } 33- \\
68 \% \text { in aerobic } \\
\text { treatment }\end{array}$ & [148] \\
\hline & $\begin{array}{l}\text { Pre-treatment to } \\
\text { aerobic digestion }\end{array}$ & $\begin{array}{l}\text { Ultrasonication at } 20 \mathrm{kHz} \\
\text { and } 0.75 \mathrm{~W} / \mathrm{cm}^{3} \text { for } 60 \mathrm{~min}\end{array}$ & Di(2-ethylhexyl)phthalate & $\begin{array}{l}\text { Increased di(2- } \\
\text { ethylhexyl)phthalate } \\
\text { removal of aerobic } \\
\text { digestion from } 72 \text { to } \\
89 \%\end{array}$ & [145] \\
\hline \multirow{3}{*}{ Thermal treatment } & $\begin{array}{l}\text { Pre-treatment to } \\
\text { anaerobic } \\
\text { digestion } \\
\end{array}$ & $\begin{array}{c}\text { Autoclaving at } 130^{\circ} \mathrm{C} \text { for } 1 \\
\text { hour }\end{array}$ & $\begin{array}{l}\text { Various pharmaceuticals, } \\
\text { musks, and hormones }\end{array}$ & $\begin{array}{l}\text { No effect on TrOC } \\
\text { removal of anaerobic } \\
\text { digestion }\end{array}$ & [122] \\
\hline & $\begin{array}{l}\text { Pre-treatment to } \\
\text { anaerobic } \\
\text { digestion } \\
\end{array}$ & $\begin{array}{c}\text { Thermal hydrolysis at } \\
150^{\circ} \mathrm{C} \text { and } 5.1 \text { bar for } 2 \\
\text { hours }\end{array}$ & Nonylphenol & $\begin{array}{l}\text { No effect on TrOC } \\
\text { removal of anaerobic } \\
\text { digestion }\end{array}$ & [149] \\
\hline & $\begin{array}{l}\text { Pre-treatment to } \\
\text { anaerobic } \\
\text { digestion }\end{array}$ & $\begin{array}{c}\text { Microwave treatment at } \\
2.45 \mathrm{GHz}, 1200 \mathrm{~W} \text {, and } 35 \\
\text { bars at } 80,120 \text {, or } 160^{\circ} \mathrm{C}\end{array}$ & Various hormones & $\begin{array}{l}\text { Decreased hormones in } \\
\text { the effluent of } \\
\text { anaerobic digester by } \\
42-78 \%\end{array}$ & [123] \\
\hline
\end{tabular}


Table 3 Sludge treatment by bioagumentation with different microorganisms

\begin{tabular}{|c|c|c|c|}
\hline Organism & TrOC & Result & Reference \\
\hline $\begin{array}{c}\text { Proteiniphilum } \\
\text { acetatigenes (bacteria) }\end{array}$ & $\begin{array}{l}\text { Polycyclic } \\
\text { aromatic } \\
\text { hydrocarbons }\end{array}$ & $\begin{array}{l}\text { Improved the removal of low } \\
\text { and high molecular weight } \\
\text { polycyclic aromatic } \\
\text { hydrocarbons }\end{array}$ & {$[151]$} \\
\hline $\begin{array}{c}\text { Comamonas } \\
\text { testosterone (bacteria) }\end{array}$ & 3-chloroanline & $\begin{array}{l}\text { Increased the removal of } 3- \\
\text { chloroanline from zero to } 15 \%\end{array}$ & {$[152]$} \\
\hline $\begin{array}{c}\text { Pichia anomala, } \\
\text { Sporidiobolus } \\
\text { salmonicolor, Pichia } \\
\text { guilliermondii, } \\
\text { Rhodotorula } \\
\text { dairenensis, and a } \\
\text { Candida maltosa-like } \\
\text { strain (yeasts) }\end{array}$ & $\begin{array}{l}\text { chrysene and } \\
\text { benzo(a)pyrene }\end{array}$ & $\begin{array}{l}\text { Imroved removals of chrysene } \\
\text { and benzo(a)pyrene from } \\
\text { negligible to } 81 \text { and } 91 \% \text {, } \\
\text { respectively }\end{array}$ & {$[153]$} \\
\hline \multirow{5}{*}{$\begin{array}{l}\text { Trametes versicolor } \\
\text { (fungi) }\end{array}$} & $\begin{array}{l}\text { Various } \\
\text { pharmaceuticals } \\
\text { and polycyclic } \\
\text { aromatic } \\
\text { hydrocarbons }\end{array}$ & $\begin{array}{l}\text { a) Resulted to } 40-100 \% \text { and } \\
3-100 \% \text { removal of various } \\
\text { pharmaceuticals and } \\
\text { polycyclic aromatic } \\
\text { hyrdrocarbons, respectively, } \\
\text { from sterilised sludge } \\
\text { b) Decreased sludge toxicity } \\
\text { (compared to sterilised } \\
\text { sludge) }\end{array}$ & {$[10]$} \\
\hline & Sulfamethazine & $\begin{array}{l}\text { Resulted to the complete } \\
\text { removal of sulfamethazine from } \\
\text { sterilised sludge }\end{array}$ & {$[154]$} \\
\hline & $\begin{array}{c}\text { Various } \\
\text { pharmaceuticals }\end{array}$ & $\begin{array}{l}\text { a) } \begin{array}{l}\text { Resulted to } 60-100 \% \\
\text { removal of various } \\
\text { pharmaceuticals from non- } \\
\text { sterilised sludge } \\
\text { b) Loss of } T \text {. versicolor } \\
\text { activity after } 21 \text { days of } \\
\text { treatment }\end{array} \\
\end{array}$ & [155] \\
\hline & $\begin{array}{c}3-(4 '- \\
\text { methylbenzylidene }) \\
\text { camphor and } \\
\text { benzophenone-3 }\end{array}$ & $\begin{array}{l}\text { Resulted to } 87-100 \% \text { removal } \\
\text { of } 3-(4 \text { '-methylbenzylidene), } \\
\text { camphor, benzophenone-3, and } \\
\text { their metabolites from sterilised } \\
\text { sludge }\end{array}$ & [156] \\
\hline & $\begin{array}{l}\text { Various } \\
\text { pharmaceuticals, } \\
\text { brominated flame } \\
\text { retardants, and UV } \\
\text { filters } \\
\end{array}$ & $\begin{array}{l}\text { Re-inoculation of } T \text {. versicolor } \\
\text { at the } 22^{\text {nd }} \text { day of treatment } \\
\text { caused }>80 \% \text { of the trace } \\
\text { organic compounds from non- } \\
\text { sterilised sludge }\end{array}$ & [157] \\
\hline
\end{tabular}


